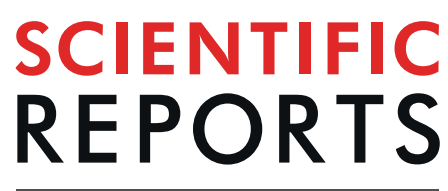

natureresearch

\title{
Slc20a1/Pit1 and Slc20a2/Pit2 are essential for normal skeletal myofiber function and survival
}

\author{
Sampada Chande ${ }^{1}$, Daniel Caballero' ${ }^{1}$, Bryan B. $\mathrm{Ho}^{1}$, Jonathan Fetene ${ }^{1}$, Juan Serna ${ }^{1}$, \\ Dominik Pesta ${ }^{2,5}$, Ali Nasiri ${ }^{2}$, Michael Jurczak ${ }^{1,4}$, Nicholas W. Chavkin ${ }^{6}$, Nati Hernando ${ }^{7}$, \\ Cecilia M. Giachelli ${ }^{6}$, Carsten A. Wagner ${ }^{7}$, Caroline Zeiss ${ }^{3}$, Gerald I. Shulman ${ }^{1,2}$ \& \\ Clemens Bergwitz ${ }^{1 *}$
}

Low blood phosphate $(\mathrm{Pi})$ reduces muscle function in hypophosphatemic disorders. Which $\mathrm{Pi}$ transporters are required and whether hormonal changes due to hypophosphatemia contribute to muscle function is unknown. To address these questions we generated a series of conditional knockout mice lacking one or both house-keeping Pi transporters Pit1 and Pit2 in skeletal muscle (sm), using the postnatally expressed human skeletal actin-cre. Simultaneous conditional deletion of both transporters caused skeletal muscle atrophy, resulting in death by postnatal day P13. smPit1 ${ }^{-l-}$, smPit2 $^{-l-}$ and three allele mutants are fertile and have normal body weights, suggesting a high degree of redundance for the two transporters in skeletal muscle. However, these mice show a gene-dose dependent reduction in running activity also seen in another hypophosphatemic model (Hyp mice). In contrast to Hyp mice, grip strength is preserved. Further evaluation of the mechanism shows reduced ERK1/2 activation and stimulation of AMP kinase in skeletal muscle from smPit ${ }^{-1-} ;$ smPit2 $^{-1-}$ mice consistent with energy-stress. Similarly, $\mathrm{C} 2 \mathrm{C} 12$ myoblasts show a reduced oxygen consumption rate mediated by Pi transport-dependent and ERK1/2-dependent metabolic Pi sensing pathways. In conclusion, we here show that Pit1 and Pit2 are essential for normal myofiber function and survival, insights which may improve management of hypophosphatemic myopathy.

Inorganic phosphate $(\mathrm{Pi})$ is involved in various cellular processes including DNA and cell membrane synthesis, signal transduction, ATP production, and bone mineralization. Serum Pi is regulated by a hormonal bone-parathyroid-kidney axis consisting of fibroblast growth factor 23 (FGF23), parathyroid hormone (PTH), and $1,25(\mathrm{OH})_{2}-\mathrm{D}$ (calcitriol) $)^{1}$. Familial disorders of $\mathrm{Pi}$ homeostasis are caused by mutations in components of this axis that either directly or indirectly (via homeostatic mechanisms) lower serum Pi levels. Furthermore, chronic hypophosphatemia is observed in the often vitamin $\mathrm{D}$-, and therefore $\mathrm{Pi}-$, deficient elderly population ${ }^{2}$.

How muscle weakness develops in these hypophosphatemic conditions, which Pi transporters are involved and whether the homeostatic hormonal changes, which develop as a result of hypophosphatemia, contribute to reduced muscle function is poorly understood. Previous studies suggest that decreased $\mathrm{ATP}^{3,4}$ and phosphodiesters $^{5}$ may in part explain the muscle weakness seen in hypophosphatemia. We recently reported that hypophosphatemic myopathy goes along with reduced ATP flux $\left(\mathrm{V}_{\mathrm{ATP}}\right)$ and intracellular Pi in an individual with hereditary hypophosphatemic rickets with hypercalciuria (HHRH) and in the sodium-Pi co-transporter Npt2a null mouse model of this disorder ${ }^{6}$. Basal and insulin-stimulated muscle $V_{\text {ATP }}$ and Pi uptake have furthermore been shown to be decreased in the offspring of patients with type 2 diabetes $^{7}$.

\footnotetext{
${ }^{1}$ Department of Internal Medicine, Section Endocrinology, Yale University School of Medicine, New Haven, CT, USA. ${ }^{2}$ Department of Cellular\&Molecular Physiology, Yale University School of Medicine, New Haven, CT, USA. ${ }^{3}$ Comparative Medicine, Yale University School of Medicine, New Haven, CT, USA. ${ }^{4}$ Department of Medicine, Division of Endocrinology, University of Pittsburgh, University of Washington, Box 355061, Foege Hall Seattle, WA, 98195, USA. ${ }^{5}$ German Diabetes Center, Düsseldorf, Germany, University of Washington, Box 355061, Foege Hall Seattle, WA, 98195, USA. ${ }^{6}$ Department of Bioengineering, University of Washington, Box 355061, Foege Hall Seattle, WA, 98195, USA. ${ }^{7}$ Institute of Physiology, University of Zürich, Switzerland and National Center of Competence in Research NCCR Kidney.CH, Zürich, Switzerland. *email: clemens.bergwitz@yale.edu
} 
While these studies support a direct role for $\mathrm{Pi}$ as a substrate for mitochondrial ATP production, it is not clear whether extracellular Pi needs to enter skeletal muscle to improve $V_{\text {ATP }}$ and muscle function, and which Pi transporters and intracellular signaling pathways are involved. Pit1 and Pit2 are type III sodium-Pi co-transporters encoded by Slc20a1 and Slc20a2 $2^{8}$. Initially discovered as retroviral receptors, ${ }^{9,10}$, they since have been shown to be ubiquitously expressed Pi-transporters in mammals. Pi-uptake via Pit1 has been shown to maintain ATP levels in pre-osteoblasts ${ }^{11}$ and chondrocytes ${ }^{12}$, and it is possible that Pit1 has similar functions in other tissues, including skeletal muscle. In support of a role for Pit1 in skeletal muscle ATP production, Pit1 and Pi levels appear to correlate with fiber-type, with slow twitch having greater levels of Pit 1 and Pi than fast twitch fibers ${ }^{13,14}$, perhaps because slow twitch fibers require more Pi transport to maintain their high oxidative capacity. However, no skeletal muscle phenotype has been described thus far in mice with global ablation of Slc20a1/Pit1, which causes embryonic lethality due to liver and hematopoetic abnormalities ${ }^{15}$. Likewise, mice with global ablation of Slc20a2/Pit2 are fertile, appear to thrive normally and have comparable body weights without reported skeletal muscle phenotypes ${ }^{16-19}$. Interestingly, recent evidence suggests that $P i t 1$ can stimulate cell proliferation ${ }^{20}$, gene expression $^{11}$, apoptosis ${ }^{21}$ and activation of the mitogen-activated kinases ERK1/2 in many cells including myocytes $^{11,22}$ independently of its transport activity. MAPK phosphatases (MKPs) can both positively and negatively regulate myogenesis through coordinate MAPK dephosphorylation ${ }^{23-26}$. For example, p38 MAPK is believed to be a promyogenic MAPK, while ERK1/2 has been shown to exhibit both positive and negative regulatory roles in myogenesis, and c-Jun $\mathrm{NH} 2$ terminus kinases (JNK) appears in some cases to be either dispensable or negative in myogenesis. Furthermore, muscle ablation of ERK1/2 isoforms using HSA-Cre results in severe atrophy of the soleus muscles, revealing their important role for the maintenance of myofibers and neuromuscular synapses in adult mice, particularly in type 1 slow twitch fibers ${ }^{27,28}$

Also, it is not clear whether FGF23, PTH, and $1,25(\mathrm{OH})_{2}$-D can contribute to hypophosphatemic myopathy by directly affecting muscle function in a Pi transport-independent fashion. For instance, loss-of-function mutations in the sodium-Pi transport protein $2 \mathrm{c}(S L C 34 A 3)$ gene have been associated with hypophosphatemic rickets with hypercalciuria $(\mathrm{HHRH})^{29}$, a disorder that causes renal Pi wasting, rickets and kidney stones, but muscle weakness is less pronounced in these individuals when compared to the muscle weakness seen in X-linked hypophosphatemia $(\mathrm{XLH})^{30}$ or tumor-induced osteomalacia (TIO) $)^{31}$. FGF23, which is low in HHRH, but elevated in XLH and TIO, was shown to induce left ventricular hypertrophy via activation of the calcineurin-NFAT signaling pathway $^{32}$, but whether FGF23 impacts skeletal muscle function is unclear ${ }^{33}$. Initial clinical observations from the use of a novel FGF23 neutralizing therapy ${ }^{34,35}$ in XLH have shown marked improvement in fatigue, muscle weakness and activity, suggesting that this therapy offers an advantage over standard therapy (oral Pi and calcitriol). Likewise, the Hyp mouse model for XLH has reduced running activity and grip strength, and anti-FGF23 antibodies restore normophosphatemia, endurance and grip strength ${ }^{36}$. Although no short-term effect of FGF23 on muscle function was reported in ex vivo settings ${ }^{37}$, chronic exposure to this hormone may be negative for muscle strength as shown in Dmp1 null mice ${ }^{38}$, which like Hyp mice have FGF23-dependent hypophosphatemia. In addition, in vitamin D-deficient individuals, cholecalciferol therapy was shown to improve mitochondrial activity and restore muscle function ${ }^{39,40}$. High levels of PTH have been shown to cause myopathy in mice independent of blood Pi, but the mechanism is not known ${ }^{41,42}$.

To determine the function of Pit1 and Pit2 in skeletal muscle independent of hypophosphatemia and the homeostatic endocrine changes resulting from hypophosphatemia, we generated a series of conditional knock-

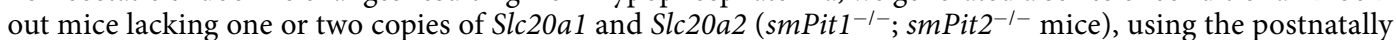
expressed human skeletal actin (HSA)-cre. These mice show a gene-dose dependent reduction in running activity resembling impaired endurance seen with hypophosphatemia, while interestingly grip strength in these mice is preserved. Furthermore, simultaneous deletion of both transporters in skeletal muscle in $s m P i t 1^{-1-}$; smPit2 $2^{-1-}$ mice is lethal postnatally due to skeletal muscle hypoplasia/atrophy with myofiber degeneration, which appears to be caused by energy-stress induced myofiber necrosis.

\section{Results}

Generation of skeletal muscle-specific Pit1/2 double knockout mice. We used semi-quantitative RT-PCR to determine that Pit1 and Pit2 are the dominant Pi importers expressed in skeletal muscle (Fig. S1A). In addition to these two Pi importers, the putative Pi exporter Xenotropic And Polytropic Retrovirus Receptor (Xpr1) and the mitochondrial Pi importer PIC/Slc25a3 are expressed at high levels. When compared to Pit1, Pit 2 mRNA levels are one order of magnitude higher in most tissues when estimated using this approach (Fig. S1B), which was verified with multiple primer sets.

To avoid the embryonic lethality observed in Pit1 knockout animals ${ }^{15}$ and to avoid possible systemic changes of $\mathrm{Pi}$ homeostasis due to global ablation of $P i t 2^{16}$ we employed a conditional approach using cre-recombinase expressed under the human skeletal muscle actin promotor postnatally ${ }^{43}$. Mutant and WT littermates were generated from a single mating strategy depicted in (Fig. 1A). We confirmed inheritance of the floxed-Pit1, -Pit2 and Cre alleles by PCR from genomic DNA prepared from tail clippings (Fig. 1B). Recombination resulting in excision of exons 3 and 4 of Pit 1 and of exon 4 of Pit 2 in quadriceps, but not in kidney, gut, brain, lung and liver was confirmed by genomic PCR (Fig. 1C) and consistent with previously reported expression of HSA-Cre using Rosa26 $6^{\text {tomato }}$ reporter mice ${ }^{44}$. Low level recombination of $P i t 1^{f l f l}$ was detected in heart (Fig. 1D and Fig. S1C), but Pit 1 and Pit 2 transcript levels were significantly decreased only in the skeletal muscle of $s m P i t 1^{-1-} ; s m P i t 2^{-1-}$ mice (Fig. 1E), whereas mRNA levels of both transporters in heart were indistinguishable from WT (Fig. S1D).

smPit1 ${ }^{-I-} ;$ smPit2 ${ }^{-I-}$ mice develop a severe myopathy and die before two weeks of life. Life birth frequency was close to expected based on Mendelian inheritance with occurrence of a few stillbirths as reflected in the dead/ungenotyped/missing pup number in (Table S3). Growth retardation of $s m P i t 1^{-1-}$; smPit ${ }^{-1-}$ mice was evident by P2 (Fig. 2A,B), accompanied by low radiographic bone density (Fig. 2C) and 
A



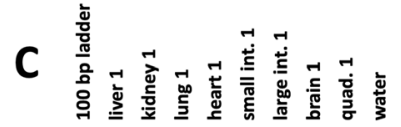

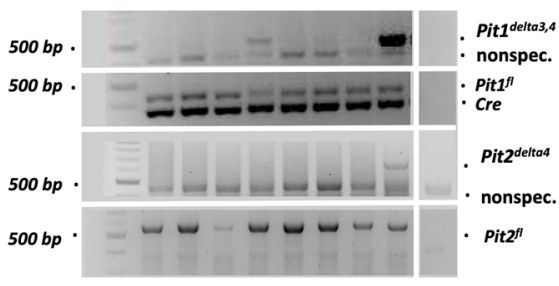

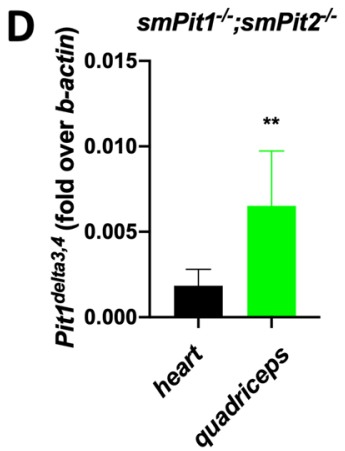


Figure 1. Generation of skeletal muscle-specific $s m P i t 1^{-1-} ; s m P i t 2^{-1-}$ double knockout mice. (A) Mating scheme used to target ablation of Pit1 and Pit2 in postnatal skeletal muscle with the human skeletal actin (HSA) promoter Cre. (B) Genotyping PCR for Pit ${ }^{f l}$, HSA-Cre, and Pit $1^{w t}$. (C) Genotyping PCR for the recombinant Pit $1^{\text {delta3,4 }}$ and Pit $2^{\text {delta } 4}$ in various tissues of a smPit $1^{-1-} ;$ smPit $^{-1-}$ mouse at P10. For raw images see supplement. (D) Semi-quantitative qenomic PCR showed $20 \%$ reduced expression of the recombinant Pit ${ }^{\text {delta } 3,4}$ in heart when compared to quadriceps. For raw images see supplement. (E) Semi-quantitative RT-PCR showed reduced expression of Pit 1 and Pit 2 in quadriceps muscle of smPit $1^{-1-}$ and smPit $2^{-1-}$ mice at P80, respectively. Means \pm SEM, $n=5-8,{ }^{* * * *} \mathrm{p}=0.0002,{ }^{* *} \mathrm{p}=0.002,{ }^{*} \mathrm{p}=0.03$ vs. WT.

by P10 they had severely impaired mobility (Video V1), inconsistent gastric filling (Fig. 2B) and depleted white adipose stores (Fig. S2D), suggesting that competition for food became progressively challenging for mutants. As a result, all $s m P i t 1^{-1-}$; smPit2 $2^{-1-}$ mice died due to hyponutrition by P13. Failure-to-thrive developed likely secondary to myopathy, since myopathy preceded weight loss, was evident at birth and progressed to marked atrophy and myofiber degeneration by P10 (Fig. 2D-F, Fig S2A,B). At P1-4, compared to the WT animal, myofibers in smPit $1^{-1-}$; smPit $2^{-1-}$ mice were poorly organized, thinner and displayed indistinct and irregularly distributed myofiber nuclei with increased overall cellularity. Less robust but structurally comparable sarcomere striation was evident in smPit $1^{-1-}$; smPit $2^{-1-}$ mice by light microscopy. At P10, myofiber disintegration was evident, and fibers contained multiple subsarcolemmal nuclei indicative of regenerative attempts. Cleaved caspase-3 cytoplasmic immunostaining (Fig. 2E, inset) was noted in mutant muscle but absent in WT muscle. The diaphragm (Fig. S2B) was likewise affected, while cardiac muscle was histologically normal (Fig. S2E). Skeletal and organ development was qualitatively comparable to WT littermates but quantitatively delayed (Fig. 2D, Fig. S2E). Growth retardation and hyponutrition were supported by histologic evidence of overall smaller size of every structure, atrophic intestinal villi, reduced subcutaneous adipose stores (Fig. S2D, E), and delayed appearance of ossification centers in various bones (Fig. S2C). smPit1 ${ }^{-1-}$; smPit $2^{-1-}$ mice were hypophosphatemic and showed a trend toward hyperphosphaturia at P10 (Fig. 3A, B) along with appropriately suppressed intact FGF23 levels (Fig. 3C). Despite failure to thrive, mutant animals were normoglycemic (Fig. 3D). Absolute serum BUN levels were comparable in smPit1 ${ }^{-1-}$; smPit2 ${ }^{-1-}$ and WT mice (Fig. 3E) arguing against significantly impaired renal function of smPit $^{-1-}$; smPit $2^{-1-}$ mice.

Energy-stress in smPit1 ${ }^{-I-} ;$ smPit2-I- skeletal muscle leads to myofiber necrosis. Histological changes observed in all limb, epaxial, and diaphragm muscles from smPit $1^{-1-}$; smPit $2^{-1-}$ mice include reduction of fiber area starting at P1, which worsened by P10 (Fig. 4A). Overt fiber necrosis seen at P10 under light microscopy were accompanied by a shift to thicker myofibrils (sarcomeres) seen on TEM (Fig. 4B), by reduced myoblast marker expression, and by increased type II Myh4 fast twitch muscle myosin expression in quadriceps muscle (Fig. 4C). There was no evidence for diffuse rhabdomyolyis upon Evans Blue exclusion staining (Fig. S3A) or endoplasmic reticulum (ER) stress based on normal Xbp1 splicing (Fig. S3B) and Chop expression (Fig. S3C) and normal appearance of the rough ER in TEM (Fig. S3G, arrows), which was recently reported in mice lacking Pit1 in growth plate chondrocytes ${ }^{45}$. There were likewise no signs for proteasomal activation based on normal Fbxo32 expression (Fig. S3D) or for autophagy based on absence of autophagosomes in TEM (Fig. S3G and Fig. S4C,D). Conversely, ERK1/2 activation was reduced in P12 quadriceps muscle obtained from smPit ${ }^{-1-}$; smPit ${ }^{-1-}$ mice, and AMPK phosphorylation was increased (Fig. 4D), consistent with increased energy-stress and reduced muscle ATP production previously described by $\mathrm{us}^{6}$ in the setting of hypophosphatemia. Evaluation 
A
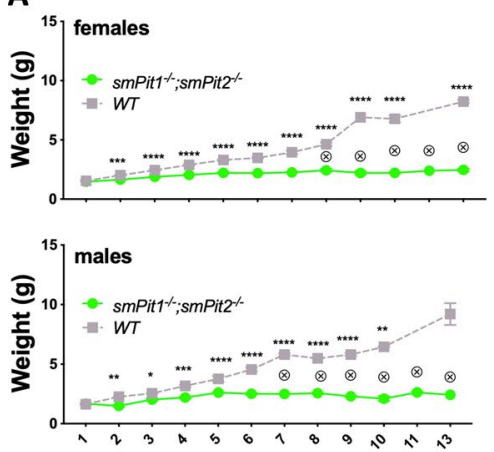

Days

B

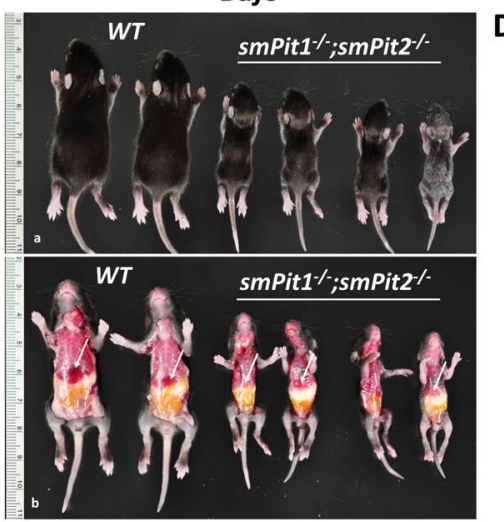

C
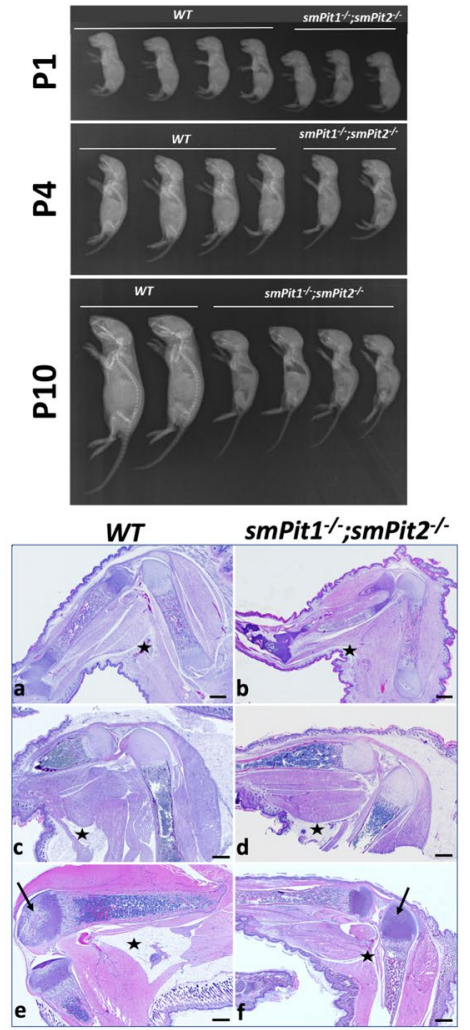

E

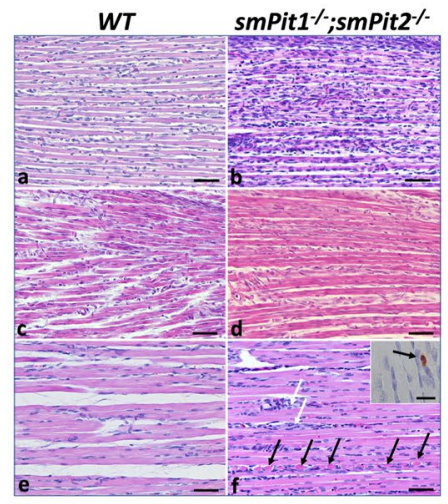

$\mathbf{F}$

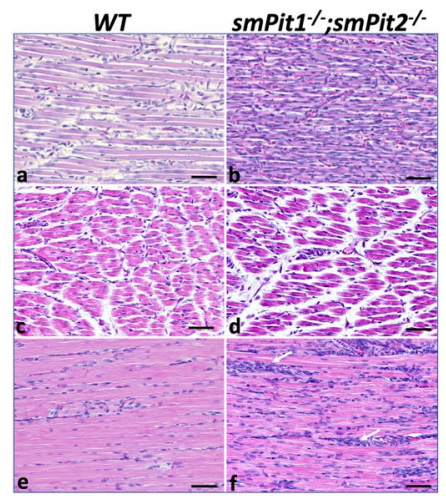

Figure 2. smPit $1^{-1-}$; smPit $2^{-1-}$ mice die before two weeks of life due to starvation. (A) Growth retardation in smPit $1^{-1-}$; smPit $2^{-1-}$ mice was evident by P2. No difference was observed attributable to presence of HSA-Cre, Pit $1^{f l}$ or Pit $2^{f l}$ (See also Fig. S6B). Means \pm SEM, $\mathrm{n}=$ indicated, $* * * * \mathrm{p}<0.00002, * * * \mathrm{p}=0.0002, * * \mathrm{p}=0.002$, $* \mathrm{p}=0.03$ vs. WT. (B) Gross phenotype (P10) shows that smPit1 ${ }^{-1-}$; smPit $2^{-1-}$ mice were much smaller but retain normal proportions, their stomachs were variably filled with milk, and their livers were atrophic (white arrow). (C) Radiographs, at P1, P4 and P10. Smaller size was evident in smPit ${ }^{-1-}$; smPit ${ }^{-1-}$ mice at P1, with reduced growth rate evident by $\mathrm{P} 4$, and markedly so by $\mathrm{P} 10$. Generalized retardation of mineralization of both axial and appendicular skeleton was noted in mutant animals. $s m P i t 1^{-1-}$; smPit $2^{-1-}$ mice were proportionately comparable to WT littermates, indicating generalized delay in growth. (D) Hind limb bone, muscle and

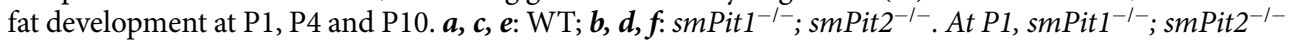
mice were slightly smaller $(\boldsymbol{b})$, and both genotypes had comparable minimal fat stores (asterisk, popliteal subcutaneous fat pad). At P4 and P10, smPit $1^{-l-}$; smPit $2^{-l-}$ mice exhibited generalized delayed growth, with reduced accumulation of skeletal muscle mass. Delayed ossification of the distal femoral epiphysis at P10 is indicated (black arrows, e, $f$ ). Subcutaneous white adipose tissue accumulated in both genotypes through P4, however by P10, this is almost entirely lost in $s m P i t 1^{-1-}$; smPit $2^{-1-}$ mice (asterisk, popliteal subcutaneous fat pad, $\boldsymbol{c}-\boldsymbol{f}$ ). H\&E, bar $=500 \mu \mathrm{m}$. (E) Muscle phenotype, anterior tibialis muscle, at P1, P4 and P10. $\boldsymbol{a}, \boldsymbol{b}$ : P1. Compared to WT $(\boldsymbol{a})$, myofibers in $s m P i t 1^{-1-} ;$ smPit $2^{-1-}$ mice $(\boldsymbol{b})$ were poorly organized, thinner, and display indistinct and irregularly distributed myofiber nuclei with increased overall cellularity. $c, d$ : P4. Myofibers in $s m P i t 1^{-1-}$; smPit2 ${ }^{-1-}$ mice $(\boldsymbol{d})$ were slightly thinner than in WT $(\boldsymbol{c})$ and had less robust but structurally comparable sarcomeric striation by light microscopy. $\boldsymbol{e}, \boldsymbol{f}$ : P10. Compared to WT (e), myofibers in $s m P i t 1^{-1-}$; smPit $2^{-1-}$ mice $(f)$ were thinner, with abundant interstitial cellularity (white arrows), and frank myofiber disintegration (black arrows). Sarcomeric striation was retained but was less robust. Cleaved caspase-3 cytoplasmic immunostaining was noted in mutant muscle (inset). H\&E, bar $=50 \mu \mathrm{m}(\boldsymbol{a}-\boldsymbol{f}), 20 \mu \mathrm{m}$ (Inset, $\boldsymbol{f})(\mathbf{F})$ Muscle phenotype, quadriceps femoris muscle, at P1, P4 and P10. $a, b$ : P1. Compared to WT (a), myofibers in

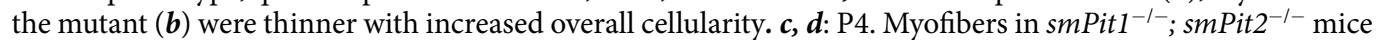
$(\boldsymbol{d})$ were thinner than in WT $(\boldsymbol{c})$, with less evident sarcomeric striation by light microscopy. Interstitial regions are expanded in mutant muscle. $\boldsymbol{e}, \boldsymbol{f}$ : P10. Compared to WT $(\boldsymbol{e})$, myofibers in smPit $1^{-1-}$; smPit $2^{-l-}$ mice $(\boldsymbol{f})$ were thinner, with scattered aggregates of increased interstitial cellularity (white arrows). $\mathrm{H} \& \mathrm{E}, \mathrm{bar}=50 \mu \mathrm{m}$.

by TEM showed reduced muscle mitochondrial area (Fig. 4E), distended mitochondrial cristae and irregular mitochondrial matrix (Fig. S4C, D). Furthermore, a small, non-significant decrease of mitochondrial DNA was seen by semi-quantitative genomic PCR (Fig. S4B). Semi-quantitative RT-PCR analysis (Fig. 4F), furthermore, showed decreased expression of the Pi transporter Slc25a3, the mitochondrial mitofusin 2, the glycolytic enzymes phosphoglycerate kinase (Pgk1) and pyruvate kinase $(P k m 1 / 2)$, while putative Pi exporter Xpr 1, peroxisome proliferator-activated receptor gamma coactivator 1 alpha (Pgcla) and Fis1 expression was unchanged and mitochondrial transcription factor A (Tfam) expression was increased. 
A

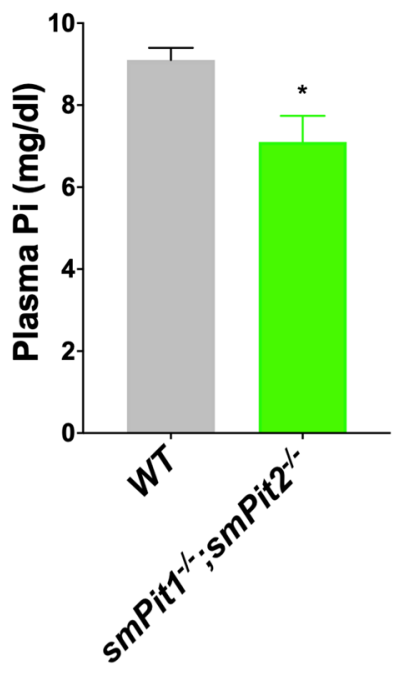

D

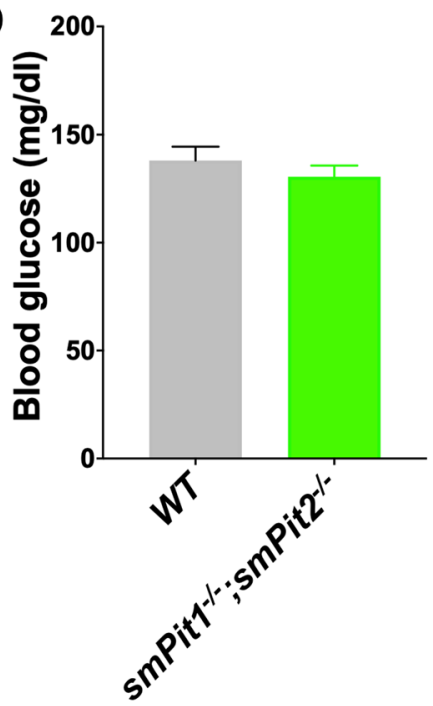

B

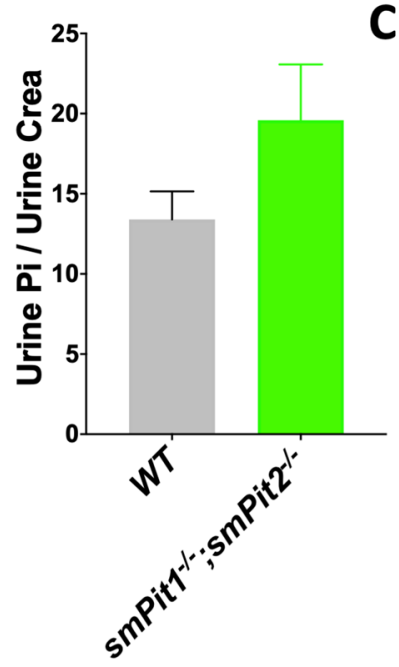

$\mathbf{E}$

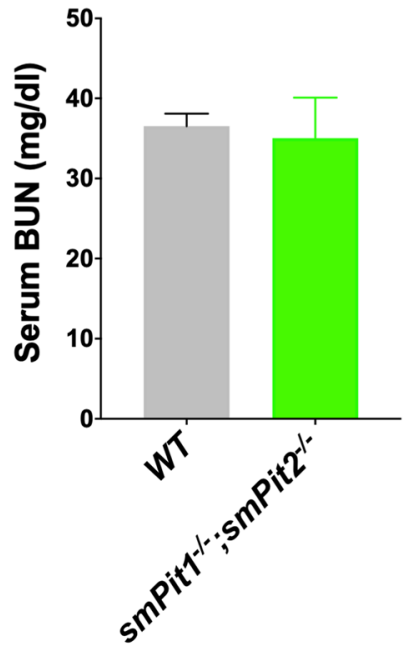

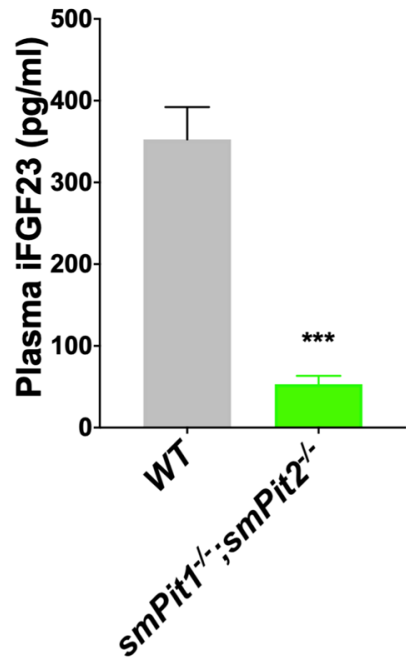

Figure 3. Skeletal muscle ablation of Pit1 and Pit2 results in a mild renal Pi leak at P10. P10 smPit1 ${ }^{-/-}$; smPit2 ${ }^{-1-}$ mice were hypophosphatemic (A) and hyperphosphaturic (B) in an FGF23-independent fashion (C). Blood glucose (D) and BUN were within normal limits (E). Means \pm SEM, $n=5-10,{ }^{* * *} p=0.0002,{ }^{* *} p=0.002$, ${ }^{*} \mathrm{p}=0.03$ vs. WT.

Reduced oxygen consumption rate (OCR) in the absence of $\mathrm{Pi}$ is consistent with energy-stress in C2C12 myoblasts. We next modeled Pi effects using a Seahorse Analyzer in murine C2C12 myoblast cells. Consistent with our observation of energy-stress following Pit 1 and Pit2 transporter ablation in vivo, acute response and maximum respiration in $\mathrm{C} 2 \mathrm{C} 12$ myoblasts were reduced in the absence of $\mathrm{Pi}$ (Fig. 5A). Using permeabilized $\mathrm{C} 2 \mathrm{C} 12$ myoblast and selective substrate/inhibitor conditions we were able to test individual mitochondrial complexes. OCR increased with addition of Pi to the mitochondrial stimulation buffer (Fig. 5B). The largest Pi effect was seen when testing complex III dependent respiration following addition of glucose-3-phosphate (G3P, Fig. 5B). Stimulation of OCR by Pi requires activation of ERK1/2, since it can be blocked by pretreatment with the MEK inhibitor UO126 (Fig. 5C). Activation of ERK1/2 by Pi was previously reported for many other cell lines ${ }^{11}$ and is blocked in C2C12 cells by ablation of Pit1 and Pit2 (Fig. S5A,B), or by pre-treatment with phosphonoformic acid (PFA), an inhibitor of Pi transport ${ }^{46}$, while PFA does not block insulin-mediated activation of ERK1/2 (Fig. 5D).

Loss of three alleles of Pit1 and Pit2 in skeletal muscle impairs endurance but not grip strength. Different from smPit $1^{-1-}$; smPit $2^{-1-}$ mice, single and three allele conditional mutants were fertile, thrived normally and had body weights comparable to wildtype animals (Fig. S6D). However, voluntary wheel



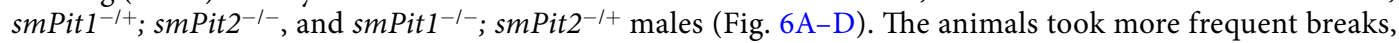
which was particularly noticeable around midnight in males (Fig. 6A). VWR activity tests endurance of predominantly slow type I muscles of the lower extremities. Interestingly, a small, but significant improvement of VWR activity was seen in $s m \mathrm{Pit}^{-1-}$ males. No difference was observed in grip strength (GS) between Pi transporter 
A
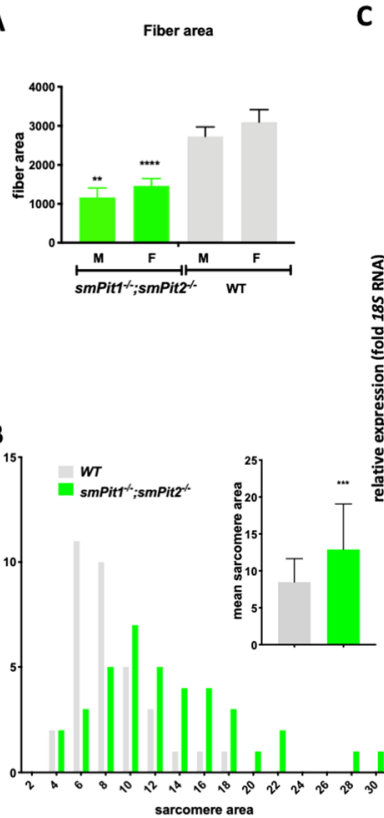

C

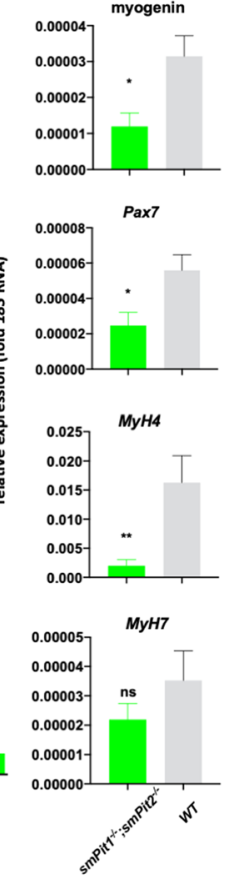

D

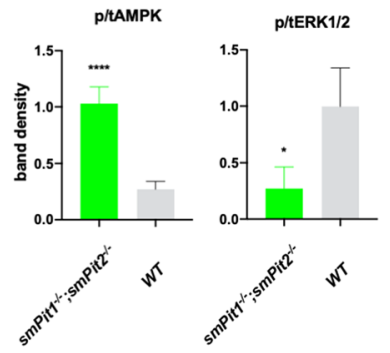

$\mathbf{E}$

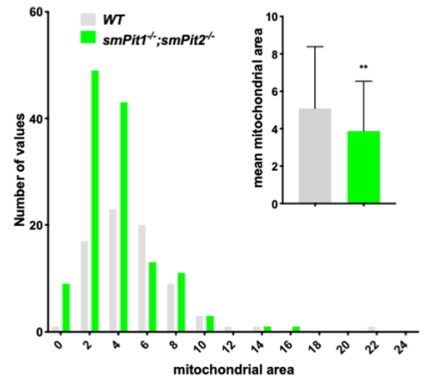

$\mathbf{F}$
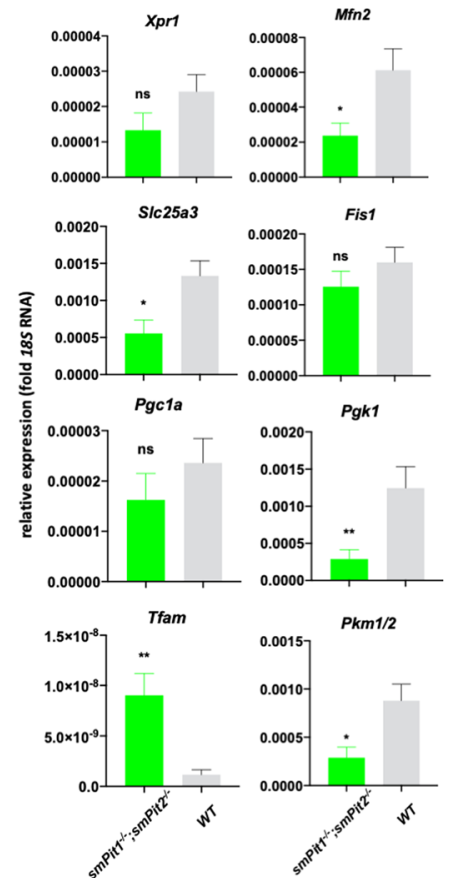

Figure 4. Energy stress results in reduced muscle fiber and increased myofibril (sarcomere) area in P10 smPit ${ }^{-1-}$; smPit/2 $2^{-1-}$ mice. (A) smPit $1^{-1-}$; smPit $2^{-1-}$ mice showed a reduction of quadriceps fiber area at P10 in paraffin sections stained with H\&E. (B) $s m P i t 1^{-1-}$; smPit $2^{-1-}$ mice showed an increased gastrocnemius myofibril (sarcomere) area at P10 in TEM. A and B show arbitrary units following ImageJ analysis of these sections on the y-axis. (C) Semi-quantitative RT-PCR showed reduced expression of myoblast markers myogenin, Pax7 and fast twitch Myh4 myosin in P10 quadriceps muscle of smPit1 ${ }^{-1-}$; smPit2 ${ }^{-1-}$ mice (D) Densitometric analysis of an immunoblot (Fig. S4A) showing increased pAMPK/tAMPK ratio and reduced pERK1/2/tERK1/2 ratio in quadriceps of four different $s m P i t 1^{-1-}$; smPit $2^{-1-}$ mice at P10. (E) Mitochondrial area and size distribution in TEM of GC at P10. (F) Semi-quantitative RT-PCR to determine gene expression of Xprl and PiC transcription factors and metabolic markers in quadriceps muscle of smPit $1^{-1-} ;$ smPit $^{-1-}$ mice at P10. Shown are means \pm SEM, $n=3-10,{ }^{* * * *} \mathrm{p}<0.00002,{ }^{* * *} \mathrm{p}=0.0002,{ }^{* *} \mathrm{p}=0.002,{ }^{*} \mathrm{p}=0.03$ vs. WT.

mutant mice and littermate controls (Fig. S6C). GS tests impact of Pi transporter ablation on fast twitch type II forearm muscles, increased significantly with age and males were stronger than females (Fig. S6A). GS was unchanged even when corrected separately for WT1 and WT2 of each breeding cohorts. No weight difference was detected for the HSA-Cre, Pit ${ }^{f l}$ or Pit $2^{f l}$ alleles (Fig. S6B,D).

\section{Discussion}

We here show that $s m P i t 1^{-/-} ; s m P i t 2^{-/-}$mice develop a severe myopathy and die soon after birth. This at first was unexpected since no apparent skeletal muscle phenotype has thus far been described in the respective single knockout mice ${ }^{15-19}$ and suggests that Pit1 and Pit2 compensate for each other in skeletal muscle. Our findings in smPit ${ }^{-1-} ;$ smPit $2^{-1-}$ mice therefore, for the first time, prove that Pit1 and Pit 2 are required for normal myocyte function and survival. Furthermore, subtle deficiencies in running wheel endurance were observed in $s m P i t 1^{-1-}$ and smPit $2^{-1-}$ mice, which might have previously been overlooked in the single global knockout mice.

Pathological evaluation showed features of skeletal myopathy at birth, when smPit1 ${ }^{-1-}$; smPit $2^{-1-}$ mice still appeared otherwise normal compared to their WT littermates, suggesting that this myopathy causes the subsequent failure-to-thrive phenotype of these mice, possibly because myopathy reduces their ability to suckle. As a result $s m P i t 1^{-1-}$; smPit $2^{-1-}$ mice died by $\mathrm{P} 13$, to which respiratory failure may contribute since their diaphragms showed similar myopathic changes. Conversely, heart failure was likely not an important contributing factor to death in these mice, since HSA-cre did not reduce transporter mRNA levels in this organ. Furthermore, cardiac muscle appeared histologically normal at the time of death of $s m P i t 1^{-/-}$; smPit2 ${ }^{-/-}$mice when compared to WT littermates.

Previous studies suggested that decreased $\mathrm{ATP}^{3,4}$ and phosphodiesters ${ }^{5}$ may in part explain the muscle weakness seen in hypophosphatemia. We recently reported that hypophosphatemic myopathy goes along with reduced ATP flux $\left(\mathrm{V}_{\mathrm{ATP}}\right)$ and IC Pi in an individual with hereditary hypophosphatemic rickets with hypercalciuria (HHRH) and in the sodium-Pi co-transporter Npt2a null mouse ${ }^{6}$. Consistent with reduced ATP production we observed activation of the energy sensor AMPK, increased Tfam expression and abnormal mitochondrial morphology in skeletal muscle of smPit $1^{-1-}$; smPit $2^{-/-}$mice, which may be a result of energy stress ${ }^{47}$ and provide an explanation for the myodegeneration and muscle necrosis seen in these mice (Fig. 7). pAMPK activates PGC1a which induces nuclear transcription of Tfam and along with p53 translocates to the mitochondria where PGC1a 
A
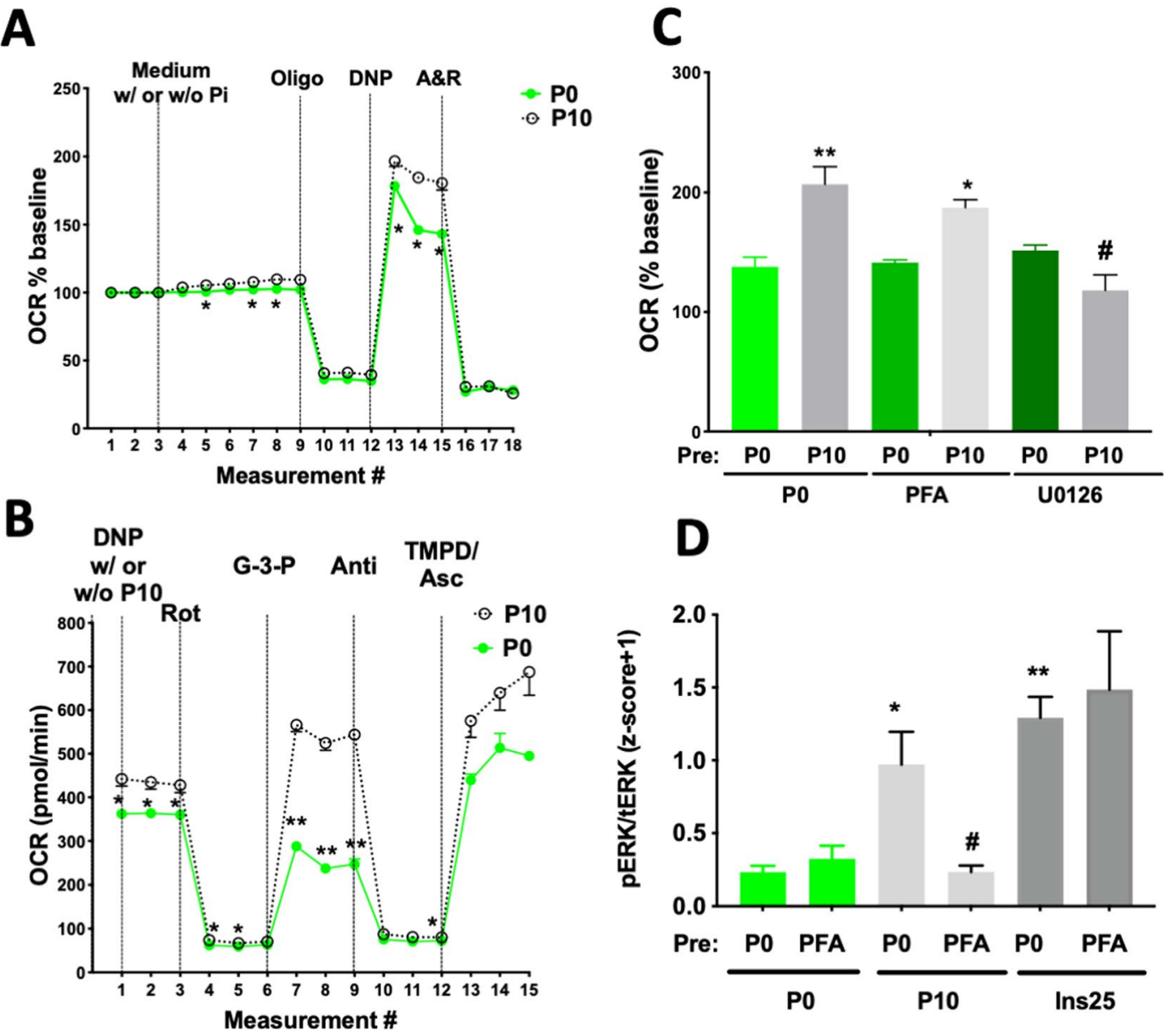

Figure 5. Respiratory chain activity of $\mathrm{C} 2 \mathrm{C} 12$ cells. (A) Individual tracing of a coupling assay using intact $\mathrm{C} 2 \mathrm{C} 12$ cells and a Seahorse XFe24 analyzer showed reduced oxygen consumption rate (OCR) in cells deprived of $\mathrm{Pi}(\mathrm{P} 0)$ when compared to cells exposed to $10 \mathrm{mM} \mathrm{Pi} \mathrm{(P10).} \mathrm{(B)} \mathrm{Individual} \mathrm{tracing} \mathrm{of} \mathrm{a} \mathrm{mitochondrial}$ electron-flow assay in permeabilized C2C12 cells in the absence (P0) and in the presence of $10 \mathrm{mM} \mathrm{Pi}(\mathrm{P} 10)$. To stimulate individual complexes, $1 \mathrm{nM}$ Plasma Membrane Permeabilizer (Seahorse) and $100 \mathrm{nM}$ dinitrophenol (DNP) was used along with $10 \mathrm{mM}$ pyruvate/ $1 \mathrm{mM}$ malate (complex C-I), $1 \mathrm{uM}$ rotenone $/ 10 \mathrm{mM}$ glycerol-3phosphate (complex C-III) or $10 \mathrm{mM}$ ascorbate/100 nM N,N,N',N'-tetramethyl-1,4-phenylenediamine (TMPD) (complex C-IV), respectively. (C) Summary of several coupling assays as described in A. Pre-treatment with phosphonoformic acid (5 mM PFA), an inhibitor of Pit1, and U0126 (30 uM), an inhibitor of MEK1/2, the kinase upstream of ERK1/2, attenuated the Pi-dependent increase in maximal respiration (D) Summary of several immunoblots of $\mathrm{C} 2 \mathrm{C} 12$ lysates following pre-treatment with $5 \mathrm{mM}$ PFA which inhibited stimulation of pERK1/2 by $10 \mathrm{mM}$ Pi (P10), but not by $25 \mathrm{uM}$ human insulin (Ins25). Densitometric results were averaged following $\mathrm{z}$-score transformation of the of individual blots. Shown are means $\pm S E M, n=3-5,{ }^{* * * *} \mathrm{p}<0.00002$, ${ }^{* * * *} \mathrm{p}=0.0002,{ }^{* *} \mathrm{p}=0.002,{ }^{*} \mathrm{p}=0.03$ vs. pre-P0/P0. ${ }^{*} \mathrm{p}=0.03$ vs pre-P0/P10 (C) and vs. pre-P0/P10 (D).

and p53 interact with Tfam to induce mitochondrial biogenesis, to improve respiratory chain function and to decrease Hifla activity as reviewed in $^{48}$. Mice lacking skeletal muscle Tfam exhibit exercise intolerance and myopathy ${ }^{49}$ resembling the one observed in $s m P i t 1^{-1-}$; smPit $2^{-1-}$ mice.

In addition to its function as a substrate for ATP production, Pi activates ERK1/2 in myocytes like in many other cells ${ }^{22}$ (Fig. 7). Consequently, ERK1/2 phosphorylation was reduced in quadriceps muscle from $s m P i t 1^{-I-}$; smPit $2^{-1-}$ mice. Our initial observations in murine C2C12 myoblasts suggest that both intracellular and membrane signaling pathways appear to be required for stimulation of mitochondrial respiration by Pi. Furthermore, expression of the muscle stem cell (MSCs) markers Pax7 and myogenin, which are known to be regulated by ERK $1 / 2^{50}$, was suppressed, and may provide a mechanism, whereby muscle stem cells (MSCs) and regeneration is impaired by ablation of Pit1 and Pit2. However, postnatal worsening of muscle degeneration and presence of multiple subsarcolemmal nuclei indicative of regenerative attempts despite low levels of these two transcription factors suggests that Pit1 and Pit2 are primarily important for muscle fiber survival.

Muscle-specific loss of ERK1/2 was also found to cause loss of neuromuscular integrity in mice ${ }^{28}$, which may contribute to the myopathy in $s m P i t 1^{-I-}$; smPit $2^{-I-}$ mice. Finally, Pit1 promotes other transport-independent processes such as proliferation ${ }^{20}$ and TNF-induced apoptosis in HeLa cells ${ }^{21}$ and insulin resistance in hepatocytes $^{51}$. These pathways may be relevant in skeletal muscle as well and may be of interest for further investigation. 
A

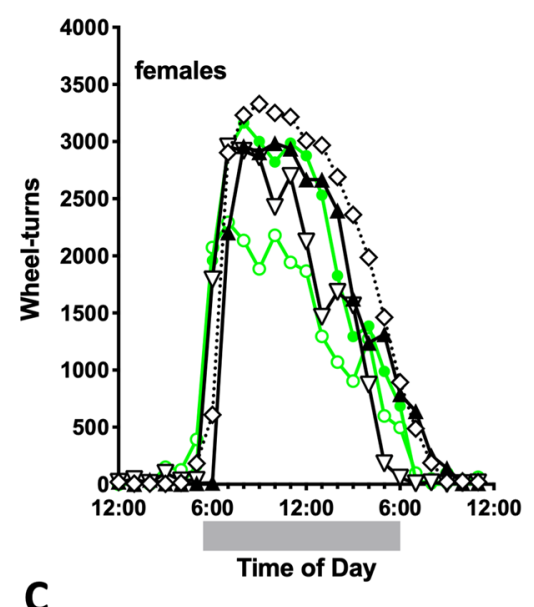

C

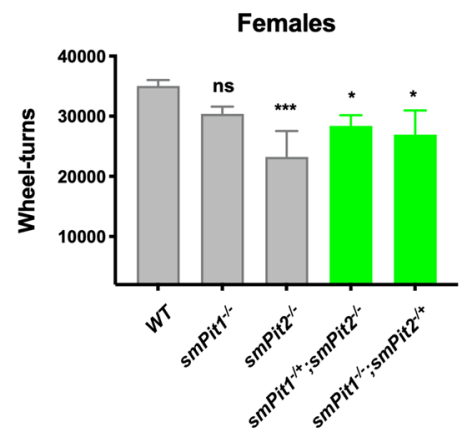

\section{B}
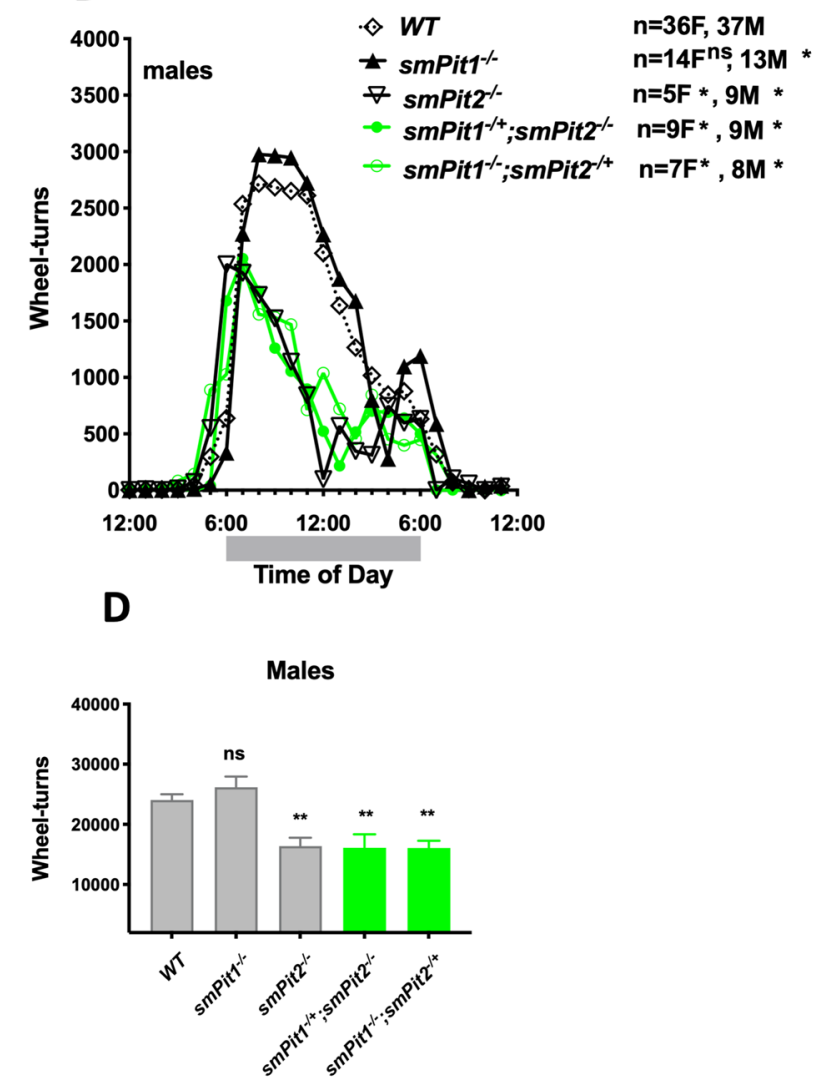

Figure 6. Loss of three alleles of skeletal muscle Pit1 and Pit2 impairs muscle function. Voluntary hourly wheelrunning activity on day 6 of a daily wheel-running study of P80 females $(\mathbf{A}, \mathbf{C})$ and males $(\mathbf{B}, \mathbf{D})$ was reduced in a gene-dose dependent fashion. Means $\pm \mathrm{SEM}, \mathrm{n}=5-36,{ }^{* * *} \mathrm{p}=0.0002,{ }^{* *} \mathrm{p}=0.002,{ }^{*} \mathrm{p}=0.03$ vs. WT.

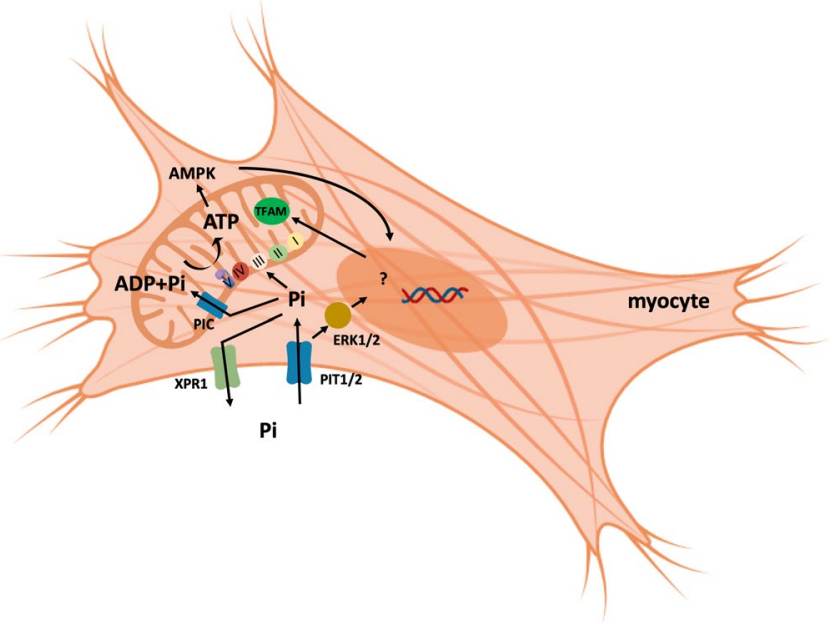

Figure 7. Metabolic Pi-signaling in myocytes. We here provide evidence for an important function of Pit1 and Pit2 to increase intracellular Pi as a substrate for mitochondrial ATP synthesis and/or as a signal to stimulate mitochondrial respiration. Pit1 and Pit2 may also serve as "transceptors" upon binding of blood Pi to activate ERK1/2 in a transport-independent fashion to stimulate myocyte proliferation and differentiation and mitochondrial respiration.

Compensation for loss of Pit1 and Pit2 in skeletal muscle may occur on the fiber, tissue and organism level and aim at reducing Pi consumption and keeping IC Pi stable. On the fiber level we observed down-regulation of the mitochondrial Pi importer Slc25A3 (PIC), increased Tfam, decreased Mfn2 levels and abnormal mitochondrial matrix, which may be aimed at improving mitochondrial function and resemble adaptive changes during exercise ${ }^{52}$. 
Mutations in human SLC25A3/PIC cause a severe myopathy affecting skeletal and cardiac muscle in humans ${ }^{53,54}$ and in mice ${ }^{55}$. Thus, down-regulation of this transporter may preserve cytosolic Pi, but since mitochondrial uptake of Pi is important for ATP synthesis, this in turn could further worsen muscular energy stress.

On the tissue level we observed a shift to a slow twitch fiber type, which may reflect a compensatory process in response to muscle energy-stress in these fibers which have greater levels of Pit1 and Pi than fast twitch fibers ${ }^{13,14}$. AMPK plays an important role in regulating muscle mass and regeneration and must be kept within relatively tight boundaries (not too high or too low) for optimal muscle regeneration ${ }^{47}$. AMPK subunit $\alpha 1$ stimulates anabolism and regulates satellite cell dynamics during regeneration, whereas AMPK subunit $\alpha 2$ regulates muscle degradation during atrophy. Energy stress predominantly activates AMPK subunit $\alpha 2$ via liver kinase B1 (LKB1), while AMPK subunit $\alpha 1$ is only activated by highly-intense or prolonged exercise, perhaps via Calcium/ calmodulin-dependent protein kinase (CamKK) action, or other AMPK kinases. AMPK subunit $\alpha 2$ stimulates catabolic processes by increasing Foxo3a, Atrogin-1 and MuRF-1 expression/activity and increasing autophagy, leading to muscle atrophy under certain circumstances, but has little effect on protein synthesis. AMPK subunit $\alpha 1$ impairs mTOR signaling, slows protein synthesis, and blocks hypertrophy. It will be of interest to determine, which AMPK isoforms contribute to the myopathy in $s m P i t 1^{-1-}$; smPit $2^{-1-}$ mice and to see, whether expression patterns likewise resemble physiological adaptation to chronic endurance exercise ${ }^{56,57}$.

On the systemic level we found that smPit $1^{-1-}$; smPit $2^{-1-}$ mice have significantly lower blood Pi levels, which appears to be a result of renal Pi excretion independent of FGF23. Since HSA-cre is not expressed in the kidneys, we speculate that skeletal muscle of $s m P i t 1^{-1-}$; smPit $2^{-1-}$ mice secretes a myocyte factor that increases renal excretion of Pi. Candidate muscle-derived factors include IGF-1, FGF-2, IL-15, irisin myostatin and L-BAIBA ${ }^{33}$, which will be subject of future investigation. Bone loss observed in these mice may be secondary to this renal Pi leak, due to direct action of one of the above myokines on bone metabolism, and/or due to failure to thrive of these mice.

Three allele mutants display reduced VWR activity which further supports the hypothesis that Pit1 and Pit2 are important predominantly for slow twitch fibers ${ }^{4-6,58}$ as already suggested by the possible shift from fast $M y h 4$ positive fibers to slow $M y h 7$ positive fibers in quadriceps muscle of $s m P i t 1^{-1-}$; smPit $2^{-1-}$ mice. Furthermore, subtle deficiencies in running wheel endurance were also observed in the single conditional mutant $s m P i t 1^{-1-}$ and smPit $2^{-1-}$ mice, which may have been previously missed during evaluation of the global knockouts for these genes ${ }^{15-19}$. Interestingly, GS is not affected in mice lacking two or three transporter alleles, which is different from observations in the Hyp mouse model for XLH that displays reduced GS along with reduced VWR activity, and which both are restored by treatment of Hyp mice with anti-FGF23 antibodies ${ }^{36}$. Likewise, ex-vivo tetanic strength was impaired in Dmp1 null mice ${ }^{38}$, which like Hyp have elevated FGF23 levels. It is thus conceivable that FGF23 impacts skeletal muscle function ${ }^{33}$ similar to its effect on the cardiac muscle ${ }^{32}$. Our Pit1 and Pit2 three allele knockout mice may be a good model to separate effects of hypophosphatemia from effects caused by adaptive hormonal changes as a result of hypophosphatemia and improve our understanding of the pathophysiology of the myopathy seen in hypophosphatemic disorders such as HHRH or XLH ${ }^{59}$.

Our observations are currently limited by the early failure-to-thrive phenotype of the smPit ${ }^{-1-}$; smPit $2^{-1-}$ mice. To further evaluate the role of Pit1 and Pit2 for muscle function and survival in adult mice, we next plan to use an inducible muscle-specific Cre, for example HSA-Cre ${ }^{r t T A 60}$. Also oral and parenteral Pi supplementation to normalize blood Pi in smPit $1^{-1-}$; smPit $2^{-1-}$ and three allele knockout mice could be attempted, however, placental Pi transport appears to isolate pups from dietary changes of $\mathrm{Pi}$ in the mother ${ }^{61}$ and thus such pharmacological rescue experiments are likely only feasible postnatally. Of interest will also be genetic rescue experiments using a cross of $s m P i t 1^{-1-}$; smPit $2^{-1-}$ mice with transgenic mice ${ }^{62}$ or adenoviral constructs expressing WT and transport-deficient [K71]hPIT1,

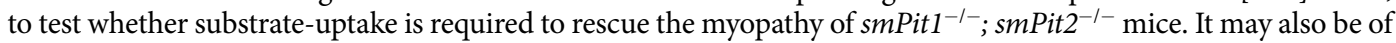
interest to test whether ablation of Xpr1 can rescue the myopathy. Xpr1 showed a trend toward what may be interpreted as compensatory down regulation in Fig. $4 \mathrm{~F}$ and was recently shown to be a widely expressed putative Pi exporter ${ }^{63,64}$, however, its functions in skeletal muscle are completely unknown. Xpr1 contains an SPX motif, which binds inositol-pyrophosphate (5-Ins $\mathrm{P}_{7}$ ), a compound shown in yeast to communicate IC Pi levels and to regulate the Pi starvation response ${ }^{65}$. Human mutations in XPR1 cause primary familial brain calcification ${ }^{63,64}$. Kidney-specific deletion of $X p r 1$ leads to a decrease in the $\mathrm{NAD}+/ \mathrm{NADH}$ ratio with reduced availability of $\mathrm{NAD}+$ for synthetic processes and development of Fanconi syndrome ${ }^{66}$. As a result, down-regulation of this transporter may preserve cellular Pi and reduce Pi consumption through synthetic processes.

In conclusion, we here show for the first time that Pit 1 and Pit 2 are essential for normal myofiber function and survival. Hypophosphatemic myopathy is currently treated with Pi supplementation ${ }^{30,59}$. However, Pi supplements are poorly tolerated and can cause intestinal symptoms, renal calcifications and secondary hyperparathyroidism ${ }^{67}$. Insights gained from $s m P i t 1^{-1-} ; s m P i t 2^{-1-}$ and three allele knockout mice suggest, that optimizing AMPK and ERK1/2 signaling and modification of XPR 1 and PIC/SLC25A3 activity may offer alternative strategies for the treatment of hypophosphatemic myopathy.

\section{Methods}

Mice and diets. smPit $1^{-1-}$ and smPit $2^{-1-}$ mice, which selectively lack the Pi transporters Pit1(Slc20a1) and Pit2 (Slc20a2), respectively, in skeletal muscle were generated using Pit ${ }^{f l / f l}$ mice obtained from Dr. Giachelli ${ }^{68}$, and HSA-Cre mice obtained from Jackson Laboratory (human skeletal actin-Cre, B6.Cg-Tg(ACTA1-cre) ${ }^{79 J m e / J}$; Jackson stock No: 006149) ${ }^{43}$. Embryonic stem cell clone EPD0243_1_C06 with loxP sites flanking exon-4 of the Slc20a2/Pit2 gene were purchased from the International Knockout Mouse Consortium (IKMC), European Conditional Mouse Mutagenesis Program (EUCOMM). Exon-4, which contains $89 \mathrm{bp}$, encodes for amino acids 144-172 and its Cre-mediated removal leads to a frame shift and an early stop codon 340 bp downstream. Conditional-ready Pit2 mice were generated by morula aggregation in the Labortierkunde (LTK) of the University of Zurich and mated with Flp-deleter mice (63Flp3B6) purchased from the Jackson Laboratory to generate Pit ${ }^{f l / f l}$ mice (Pastor-Arroyo et al, in preparation) ${ }^{69}$. 
All mice were generated from a C57Bl/6 background and experimental mice were generated using the mating strategy of Pit $1^{f l /+}$; Pit $2^{f l /+}$ females x Pit $1^{f l /+}$; Pit $2^{f l+}$; HSA-Cre $e^{t g /+}$ males and Cre-negative littermates were used as controls to minimize bias related to a specific genetic background. Mice were weaned at 3 weeks of age and allowed free access to water and standard chow (1.0\% calcium, 0.7\% Pi (0.3\% bioaccessible Pi; TD.2018S; Harlan Teklad, Madison, WI, USA).

Genotyping at weaning was performed by PCR amplification of genomic DNA extracted from tail clippings using the HotSHOT method ${ }^{70}$ and amplified by polymerase chain reaction (PCR) as previously described ${ }^{71}$ using $^{-}$ the primers shown in Table S1. Briefly, $75 \mathrm{uL}$ alkaline lysis buffer $(25 \mathrm{mN} \mathrm{NaOH}, 0.2 \mathrm{mM}$ EDTA $)$ was aliquoted to $1.5 \mathrm{~mL}$ tubes containing tissue. Lysates were incubated for $30 \mathrm{~min}$ at $95^{\circ} \mathrm{C}$, then neutralized with $75 \mathrm{uL}$ neutralization buffer ( $40 \mathrm{mM}$ Tris- $\mathrm{HCl})$. Genomic DNA was amplified by PCR to genotype mice and determine skeletal muscle-specific ablation of Pit1. Primer pairs used were: wild-type (Pit $1^{\text {wt }}$ ) and Pit1-floxed (Pit $\left.1^{f l}\right)(\mathrm{F}) 819$ and (R) 820; wild-type $\left(\right.$ Pit $\left.^{w t}\right)$ and delta allele (Pit1 $\left.{ }^{\Delta e 3,4}\right)$ : (F) 819 and (R) 822; ACTA1-cre (HSA-Cre): (F) 823 and (R) $824^{68}$ and wild-type $\left(\right.$ Pit2 $\left.^{w t}\right)$, Pit2-floxed $\left(\right.$ Pit $\left.^{f f}\right)$ (F) 954 and (R) 955, and delta allele (Pit2 $\left.{ }^{\Delta e 4}\right)$ (F) 995 and (R) 996 (Table S1).

Animal research for this study was first approved on October 22, 2014 by the Yale Institutional Animal Care and Use Committee (protocol 2014-11635), was renewed on September 7, 2016, and is valid through Sept. 30, 2020. Yale University has an approved Animal Welfare Assurance (\#A3230-01) on file with the NIH Office of Laboratory Animal Welfare. The Assurance was approved on May 5, 2015.

Anatomic phenotyping. A total of 34 animals (Table S2) across 5 litters (P1, P4, P8 and P10) were examined grossly. These included $13 \mathrm{smPit1^{-1- }}$; smPit $2^{-1-}$ animals with wild-type animals comprising the balance. Animal histopathology was performed on 21 animals (indicated by histopathology numbers in Table S2). Of these, images from animals at P1, P4, and P10 were used to illustrate pathologic findings. Animals were evenly split by sex and genotype. All the methods for the study were carried out in accordance with relevant guidelines and according to the 2013 AVMA guidelines for the euthanasia of animals. Following gross photography, radiography and collection of blood for glucose measurement, soft and bony tissues from all animals were immersed in $10 \%(\mathrm{w} / \mathrm{v})$ neutral buffered formalin or Bouin's solution respectively for one week. Cassetted tissues were embedded in paraffin, sectioned at $5 \mu \mathrm{m}$, and mounted on glass slides. Sections were stained with hematoxylin and eosin (H\&E), examined using a Zeiss Axioskop light microscope and imaged using a Zeiss AxioCam MrC camera.

Transmission electron microscopy. For transmission electron microscopy a $1 \mathrm{~mm}^{3}$ block of the left kidney was fixed in $2.5 \%$ glutaraldehyde and $2 \%$ paraformaldehyde in $0.1 \mathrm{M}$ Cacodylate buffer for 2 hrs., followed by post-fixation in $1 \%$ osmium liquid for 2 hours. Following dehydration using a series of ethanol concentrations (50\% to $100 \%$ ), tissue was embedded in epoxy resin, and polymerization was carried out at $60^{\circ} \mathrm{C}$ for overnight as previously described ${ }^{62}$. After preparing a thin section $(50 \mathrm{~nm})$, the tissues were double stained with uranium and lead and observed using a Tecnai Biotwin (LaB6, $80 \mathrm{kV}$ ) (FEI, Thermo Fisher, Hillsboro, OR) at the Yale Center for Cellular and Molecular Imaging (YCCMI).

Evan's Blue staining. To evaluate muscle fiber integrity, 1\% Evans blue dye dissolved in sterile saline was administered by intraperitoneal injection at a dose of $1 \%$ of body weight to WT and smPit $1^{-1-}$; smPit2 ${ }^{-1-}$ mice at age $\mathrm{P} 10$, followed by sacrifice after $24 \mathrm{hrs}$. and dissection of muscles that were snap-frozen in liquid nitrogen. Muscle cryosections of $10-\mu \mathrm{m}$ thickness were cut at $-21^{\circ} \mathrm{C}$ on a Leica (CM3050) cryostat, dipped in cold acetone $\left(-20^{\circ} \mathrm{C}\right)$ for $1 \mathrm{~min}$ and then air-dried at room temperature $\left(20-22^{\circ} \mathrm{C}\right)(\mathrm{RT})$. Sections were dipped in xylene (Merck) and mounted with DPx (BDH, Poole, UK) and a glass coverslip. Evans blue was viewed by confocal fluorescent microscopy SP8 LIGHTNING confocal microscope (Leica, Buffalo Grove, IL, USA) at $620 \mathrm{~nm}$ excitation and $680 \mathrm{~nm}$ emission as described $^{72}$.

Radiology. Following euthanasia, animals were radiographed in dorsovental and lateral recumbancy using a Universal radiology unit and AGFA Small Animal Digital Radiography system (Agfa HealthCare, Mortsel, Belgium).

Blood and urine parameters. Blood and spot urines were collected as previously described ${ }^{71}$. Glucose measurements as a measure of recent feeding were taken immediately after removal of the pups from the mother at euthanasia using a handheld glucometer (Accu-Chek, Roche, Switzerland). Creatinine levels were measured by HPLC/MS/MS commercially from serum samples collected at euthanasia (Antech, Fountain Valley, CA, USA). BUN was measured from serum samples using kit 0580 (Stanbio, Boerne, TX, USA). The COBAS Mira Plus automated chemistry analyzer (Roche Diagnostics, Pleasanton, CA, USA) was used to determine plasma and urine inorganic phosphorus. Urinary creatinine was measured by colorimetric assay (DICT-500; BioAssay Systems, Hayward, CA, USA). Concentrations of serum intact fibroblast growth factor (FGF)-23 protein were determined using mouse FGF-23 ELISA assays (60-6500; Immutopics, San Clemente, CA, USA).

Muscle physiology. Forelimb grip strength was measured with the Mouse Grip Strength Meter (1027SM; Columbus Instruments, Columbus, OH, USA) at ages 30, 60, and 120 days. The average grip strength was calculated from three trials conducted in series. Voluntary wheel-running (VWR) was assessed using home cages equipped with running wheels (0297-8; Columbus Instruments) using experimental procedures previously described by other groups at the Yale School of Medicine ${ }^{73,74}$. Briefly, mice were individually housed for one week and maintained on a $12 \mathrm{~h}$ light/dark cycle. Food and water were provided ad libitum. The number of wheel-turns was continuously recorded by ClockLab software (Actimetrics, Wilmette, IL, USA). Data files were exported to MATLAB and converted to Excel spreadsheets using Clocklab Analysis (Actimetrics, Wilmette, IL, USA). 
Genomic DNA and RNA extraction and allele-specific PCR from various mouse tissues and C2C12 cells. Gastrocnemius and quadriceps muscle tissue were dissected immediately following sacrifice, snap-frozen (by compression between aluminum clamps pre-chilled in liquid nitrogen), and stored at $-70^{\circ} \mathrm{C}$. Genomic DNA was extracted from tissues using the HotSHOT method ${ }^{70}$ described above. Total RNA from tissues was extracted using TRIzol (15596026; Invitrogen, Carlsbad, CA, USA). Total RNA from C2C12 cells was prepared using RNeasy columns (Qiagen, Valencia, CA). 0.5-2 ug total RNA were reverse-transcribed using the Omniscript RT Kit (205113; Qiagen, Valencia, CA, USA). Semi-quantitative genomic or reverse transcription (RT) PCR was performed with SYBR Green (204143; Quantitect, Qiagen) using the ABI-Step One Plus Cycler (Fisher, Life Technologies, Waltham, MA, USA) and analyzed using the $2-\Delta \Delta \mathrm{Ct}$ method. Primer sequences were designed using PrimerBank ${ }^{75}$ and are shown Table S1. b-actin and $18 S$ RNA gave comparable results as internal controls (see Fig. S3E,F) and ABI Cycler efficiency measures were all acceptable.

Protein extraction and immunoblot analysis from various mouse tissues and $\mathrm{C} 2 \mathrm{C} 12$ cells. Skeletal muscle tissue was homogenized as previously described ${ }^{62}$ in ice-cold RIPA buffer ( $50 \mathrm{mM}$ Tris HCL (pH 6.8), $150 \mathrm{mM} \mathrm{NaCl}, 1 \%$ Triton X-100, 0.5\% sodium deoxycholate, $0.1 \%$ sodium dodecyl sulfate, Protease inhibitor without EDTA (Roche, Mannheim, Germany), $0.4 \mathrm{mM}$ Na-orthovanadate, $50 \mathrm{mM}$ beta-GP, $5 \mathrm{mM} \mathrm{NaF}$ ). Lysates were incubated on an orbital shaker for 2 hours then centrifuged for $20 \mathrm{~min}$ at $12,000 \mathrm{~g}$ at $4{ }^{\circ} \mathrm{C}$. Protein amount was measured using a BCA assay (Thermo Fisher Scientific, Waltham, MA, USA). 50 ug of protein were run on a PAGE gel electrophoresis on 10\% Tris-HCl/Glycine SDS-polyacrylamide (456-1034, BioRad, CA), electro-transfer to PVDF membranes (162-0218, BioRad, CA, USA) and hybridized with anti-phospho-ERK1/2 (9106, Cell Signaling Technology, MA, or 4730, Cell Signaling Technology, MA, USA) or anti-total-ERK1/2 antibody (4695, Cell Signaling Technology, MA, USA) 1:1000 in phosphate buffered saline containing $0.1 \%$ Tween 20 (PBST) and $5 \%$ non-fat dry milk at $4{ }^{\circ} \mathrm{C}$ overnight, or hybridized with pAMPK rabbit antibody (2535, Cell Signaling Technology, MA, USA, the antibody detects both $\alpha 1$ and $\alpha 2$ isoforms of the catalytic subunit, but does not detect the regulatory $\beta$ or $\gamma$ subunits) 1:1000 or tAMPK rabbit antibody (2603, Cell Signaling Technology, MA, USA) 1:1000 in tris buffered saline containing $0.1 \%$ Tween 20 (TBST) and 5\% BSA (A7888, Sigma, MA, USA) at $4{ }^{\circ} \mathrm{C}$ overnight, and detected with horseradish-peroxidase conjugated anti-rabbit IgG (7074 S, Cell Signaling Technology, MA) in PBST + 5\% non-fat dry milk at room temperature for $60 \mathrm{~min}$ using chemiluminescence/autoradiography (Supersignal 34580, Thermo Fisher Scientific, Waltham, MA, USA).

For $\mathrm{C} 2 \mathrm{C} 12$ cells following pretreatment and stimulation the 48 -well plate was placed on ice and the culture medium was aspirated. Cells were then lysed with 50 ul lysis buffer $(62.5 \mathrm{mM}$ Tris HCL (pH 6.8), $1 \%$ SDS, $1 \mathrm{mM}$ EDTA, $1 \mathrm{mM}$ EGTA, $0.05 \mathrm{TiU} / \mathrm{ml}$ aprotonin, $1 \mathrm{M}$ PMSF, $100 \mathrm{mM} \mathrm{Na}$-orthovanadate, $0.8 \%$ SDS, 3.2\% glycerol, $2 \%$ beta mercaptoethanol, $0.0015 \%$ bromophenolblue). 15 ul cell lysates were then separated, electro-transferred to PVDF membranes and hybridized with anti-phospho-ERK1/2 (9106, Cell Signaling Technology, MA, USA) or (4730, Cell Signaling Technology, MA, USA) or total-ERK1/2 antibody (4695, Cell Signaling Technology, MA, USA) in phosphate buffered saline containing $0.1 \%$ Tween 20 (PBST) and $5 \%$ non-fat dry milk at $4{ }^{\circ} \mathrm{C}$ overnight and detected as described for skeletal muscle lysates above. Following densitometric analysis of the autoradiograms, phospho/total ERK ratios were converted into z-scores to permit statistical evaluation of pooled Western blot experiments.

C2C12 myoblast cell culture. C2C12 myoblasts were cultured at $37^{\circ} \mathrm{C}$ under $5 \% \mathrm{CO}_{2}$ for up to 8 weeks in high glucose DMEM ( $\mathrm{pH} 7.4$; 11965-092; Gibco, Gaitherburg, MD, USA) supplemented with 10\% fetal bovine serum (F4135; Sigma, St. Louis, MO, USA). Medium was changed every 3-4 days and cells were split (1:10) once a week with $0.25 \%$ trypsin/EDTA. Pi-free DMEM (pH 7.4; 11971-025; Gibco, Gaitherburg, MD, USA) was substituted for complete DMEM when indicated. Human insulin (91077 C, Sigma, St. Louis, MO, USA) was used at a final concentration of $25 \mathrm{ug} / \mathrm{ml}$. The MAP kinase inhibitor UO126 (19-147; Sigma, St. Louis, MO, USA) and the PI-3 kinase inhibitor Ly294002 (L9908; Sigma, St. Louis, MO, USA) were suspended in DMSO and dosed at $10 \mathrm{uM}$ and $50 \mathrm{uM}$, respectively. Phosphonoformic acid (PFA; P6801; Sigma, St. Louis, MO, USA), a weak competitive inhibitor of Pit 1 transport activity, was used at a final concentration of $5 \mathrm{mM}$.

RNAi ablation studies. C2C12 cells were seeded at 20,000/well and transfected with $20 \mathrm{nM}$ of ON-TARGETplus siRNA (Slc20a1 (Pit1, L-045288-01-0005); GE Dharmacon, Lafayette, CO, USA) using RNAiMAX (13778075; Lipofectamine, Thermo Fisher Scientific, Waltham, MA, USA) diluted in Opti-MEM (31985070; Gibco, Gaithersburg, MD, USA) for delivery. Transfected cells were cultured in Pi-free DMEM for 3 days before further analysis.

Extracellular flux analysis. Cellular respiratory activity was measured using a Seahorse XFe24 Analyzer (Agilent Technologies, Santa Clara, CA, USA). For transfection and non-transfection assays, C2C12 myoblasts were seeded at 40,000 cells/well in Pi-free DMEM (pH 7.4; with 10\% FBS and 10 mM HEPES) and cultured for 3 days. Cells were re-fed the day before the assay.

For intact cell assays, microplates were placed in a $\mathrm{CO}_{2}$ free incubator $45 \mathrm{~min}$ before the start of the assay to permit evaporation of $\mathrm{CO}_{2}$. Immediately prior to the assay, Pi-free medium was replaced with assay medium (pH 7.4; 8.3 g/l DMEM base (CM038305; Invitrogen, Carlsbad, CA, USA) with $12.5 \mathrm{mM}$ glucose, $31 \mathrm{mM} \mathrm{NaCl}$, $100 \mathrm{mM}$ pyruvate, $2 \mathrm{mM}$ Glutamax-I (35050-061; Gibco, Gaithersburg, MD, USA), and no Pi). Oxygen consumption rate (OCR) was measured in $8.5 \mathrm{~min}$ intervals. Mitochondrial respiratory activity was manipulated by serial injection of $10 \mathrm{mM}$ sodium Pi, $1.25 \mathrm{uM}$ oligomycin (an ATP synthase inhibitor), $100 \mathrm{uM}$ 2, 4-dinitrophenol (a mitochondrial uncoupler), and $1 \mathrm{uM}$ antimycin/1 uM rotenone (complex I and III inhibitors). The effect of Pi on intact cell OCR is termed as "acute response", and the following injection of oligomycin and DNP as "maximal respiration". 
Coupling and electron flow assay protocols were adapted from Divakaruni et al. ${ }^{76}$, Salabei et al. ${ }^{77}$, and the manufacturer's protocols. C2C12 cells were permeabilized with Seahorse Plasma Membrane Permeabilizer (PMP, 102504-100; Agilent Technologies, Santa Clara, CA, USA). Briefly, immediately before each assay, cells were washed once with mannitol/sucrose (MAS) buffer ( $\mathrm{pH} 7.2 ; 220 \mathrm{mM}$ mannitol, $70 \mathrm{mM}$ sucrose, $10 \mathrm{mM}$ $\mathrm{KH}_{2} \mathrm{PO}_{4}, 5 \mathrm{mM} \mathrm{MgCl}, 2 \mathrm{mM}$ HEPES, $1 \mathrm{mM}$ EGTA, and $4 \mathrm{mg} / \mathrm{mL}$ fatty acid free-bovine serum albumin) then immersed in MAS buffer containing $1 \mathrm{nM}$ PMP. OCR was measured in 3 min intervals. Mitochondrial respiratory state $3(\mathrm{ADP}+/-\mathrm{Pi}+$ substrate) for coupling assays was induced by injection of the following: $4 \mathrm{mM}$ ADP, $10 \mathrm{mM}$ sodium $\mathrm{Pi}, 10 \mathrm{mM}$ pyruvate and $1 \mathrm{mM}$ malate $(\mathrm{CI}), 10 \mathrm{mM}$ succinate $(\mathrm{CII}), 10 \mathrm{mM}$ glycerol-3-phosphate (G3P, CIII), $100 \mathrm{uM} \mathrm{TMPD}$ and $10 \mathrm{mM}$ ascorbic acid (CIV). State $4^{\circ}$ (oligomycin-dependent), maximal, and non-mitochondrial respiration were assessed by injection of chemicals mentioned above for intact cells. Electron flow assays were begun with cells immersed in MAS buffer containing PMP, DNP, and complex I-specific substrates, and additional complex-specific substrates were injected in serial order at the concentrations stated above.

Statistical and image analysis. Data are expressed as means \pm SEM and were analyzed as previously described $^{62}$ in Prism 8.0 (GraphPad Software, Inc., La Jolla, CA). Differences between groups were considered significant if $\mathrm{p}$-values obtained with Student's t-test were $<0.05$. The Mann-Whitney U test was used for comparisons when there was evidence by the Shapiro-Wilk normality test that the data were not normally distributed. Two-way ANOVA and Tukey's test for multiple comparisons was used to determine significant differences between more than two treatment groups with a significance threshold of $p<0.05$. Light and electron microscopic images were analysed using ImageJ (version2.0.0-rc-69/1.52p) to determine myofiber, myofibril (sarcomere) and mitochondrial areas.

Received: 1 December 2019; Accepted: 29 January 2020;

Published online: 20 February 2020

\section{References}

1. Bergwitz, C. \& Jüppner, H. Regulation of phosphate homeostasis by PTH, vitamin D, and FGF23. Annu. Rev. Med. 61, 91-104 (2010).

2. Sumukadas, D., Jenkinson, F. \& Witham, M. D. Associations and consequences of hypophosphataemia in older hospitalised women. Age Ageing 38, 112-115, https://doi.org/10.1093/ageing/afn244 (2009).

3. Knochel, J. P. Neuromuscular manifestations of electrolyte disorders. Am. J. Med. 72, 521-535 (1982).

4. Hettleman, B. D., Sabina, R. L., Drezner, M. K., Holmes, E. W. \& Swain, J. L. Defective adenosine triphosphate synthesis. An explanation for skeletal muscle dysfunction in phosphate-deficient mice. J. Clin. Invest. 72, 582-589, https://doi.org/10.1172/ jcil11006 (1983).

5. Ambuhl, P. M. et al. Metabolic aspects of phosphate replacement therapy for hypophosphatemia after renal transplantation: impact on muscular phosphate content, mineral metabolism, and acid/base homeostasis. Am. J. Kidney Dis. 34, 875-883 (1999).

6. Pesta, D. H. et al. Hypophosphatemia promotes lower rates of muscle ATP synthesis. FASEB J. 30, 3378-3387, https://doi. org/10.1096/fj.201600473R (2016).

7. Petersen, K. F., Dufour, S. \& Shulman, G. I. Decreased insulin-stimulated ATP synthesis and phosphate transport in muscle of insulin-resistant offspring of type 2 diabetic parents. PLoS Med. 2, e233, https://doi.org/10.1371/journal.pmed.0020233 (2005).

8. Forster, I. C., Hernando, N., Biber, J. \& Murer, H. Phosphate transporters of the SLC20 and SLC34 families. Mol. Asp. Med. 34, 386-395, https://doi.org/10.1016/j.mam.2012.07.007 (2013).

9. Kavanaugh, M. P. \& Kabat, D. Identification and characterization of a widely expressed phosphate transporter/retrovirus receptor family. Kidney Int. 49, 959-963 (1996).

10. Olah, Z., Lehel, C., Anderson, W. B., Eiden, M. V. \& Wilson, C. A. The cellular receptor for gibbon ape leukemia virus is a novel high affinity sodium-dependent phosphate transporter. J. Biol. Chem. 269, 25426-25431 (1994).

11. Camalier, C. E. et al. An integrated understanding of the physiological response to elevated extracellular phosphate. J. Cell Physiol. 228, 1536-1550, https://doi.org/10.1002/jcp.24312 (2013).

12. Sugita, A. et al. Cellular ATP synthesis mediated by type III sodium-dependent phosphate transporter Pit-1 is critical to chondrogenesis. J. Biol. Chem. 286, 3094-3103, https://doi.org/10.1074/jbc.M110.148403.

13. Scheibye-Knudsen, M. \& Quistorff, B. Regulation of mitochondrial respiration by inorganic phosphate; comparing permeabilized muscle fibers and isolated mitochondria prepared from type-1 and type-2 rat skeletal muscle. Eur. J. Appl. Physiol. 105, 279-287, https://doi.org/10.1007/s00421-008-0901-9 (2009)

14. Abraham, K. A., Brault, J. J. \& Terjung, R. L. Phosphate uptake and PiT-1 protein expression in rat skeletal muscle. Am. J. Physiol. Cell Physiol 287, C73-78, https://doi.org/10.1152/ajpcell.00510.2003 (2004)

15. Beck, L. et al. The phosphate transporter PiT1 (Slc20a1) revealed as a new essential gene for mouse liver development. PLoS One 5, e9148 (2010).

16. Bon, N. et al. Phosphate-dependent FGF23 secretion is modulated by PiT2/Slc20a2. Mol. Metab. 11, 197-204, https://doi. org/10.1016/j.molmet.2018.02.007 (2018).

17. Bourgine, A. et al. Mice with hypomorphic expression of the sodium-phosphate cotransporter PiT1/Slc20a1 have an unexpected normal bone mineralization. PLoS One 8, e65979, https://doi.org/10.1371/journal.pone.0065979 (2013).

18. Crouthamel, M. H. et al. Sodium-dependent phosphate cotransporters and phosphate-induced calcification of vascular smooth muscle cells: redundant roles for PiT-1 and PiT-2. Arterioscler. Thromb. Vasc. Biol. 33, 2625-2632, https://doi.org/10.1161/ ATVBAHA.113.302249 (2013).

19. Jensen, N. et al. Loss of function of Slc20a2 associated with familial idiopathic Basal Ganglia calcification in humans causes brain calcifications in mice. J. Mol. Neurosci. 51, 994-999, https://doi.org/10.1007/s12031-013-0085-6 (2013).

20. Beck, L. et al. Identification of a Novel Function of PiT1 Critical for Cell Proliferation and Independent of Its Phosphate Transport Activity. J. Biol. Chem. 284, e99959 (2009).

21. Salaun, C. et al. Identification of a novel transport-independent function of PiT1/SLC20A1 in the regulation of TNF-induced apoptosis. J. Biol. Chem. (2010).

22. Chande, S. \& Bergwitz, C. Role of phosphate sensing in bone and mineral metabolism. Nat. Rev. Endocrinol. 14, 637-655 (2018).

23. Shi, H. et al. Mice lacking MKP-1 and MKP-5 Reveal Hierarchical Regulation of Regenerative Myogenesis. J. Stem Cell Regen. Biol. 1, 1-7, https://doi.org/10.15436/2741-0598.15.005 (2015).

24. Shi, H. et al. Improved regenerative myogenesis and muscular dystrophy in mice lacking Mkp5. J. Clin. Invest. 123, 2064-2077, https://doi.org/10.1172/JCI64375 (2013). 
25. Shi, H. et al. MAP kinase phosphatase-1 deficiency impairs skeletal muscle regeneration and exacerbates muscular dystrophy. FASEB J. 24, 2985-2997, https://doi.org/10.1096/f.09-150045 (2010).

26. Bennett, A. M. \& Tonks, N. K. Regulation of distinct stages of skeletal muscle differentiation by mitogen-activated protein kinases. Sci. 278, 1288-1291 (1997).

27. Wang, S., Seaberg, B., Paez-Colasante, X. \& Rimer, M. Defective Acetylcholine Receptor Subunit Switch Precedes Atrophy of SlowTwitch Skeletal Muscle Fibers Lacking ERK1/2 Kinases in Soleus Muscle. Sci. Rep. 6, 38745, https://doi.org/10.1038/srep38745 (2016).

28. Seaberg, B. et al. Muscle-derived extracellular signal-regulated kinases 1 and 2 are required for the maintenance of adult myofibers and their neuromuscular junctions. Mol. Cell Biol. 35, 1238-1253, https://doi.org/10.1128/MCB.01071-14 (2015).

29. Bergwitz, C. et al. SLC34A3 mutations in patients with hereditary hypophosphatemic rickets with hypercalciuria predict a key role for the sodium-phosphate cotransporter NaPi-IIc in maintaining phosphate homeostasis. Am. J. Hum. Genet. 78, 179-192, https:// doi.org/10.1086/499409 (2006).

30. Carpenter, T. O., Imel, E. A., Holm, I. A., Jan de Beur, S. M. \& Insogna, K. L. A clinician's guide to X-linked hypophosphatemia. J. Bone Min. Res. 26, 1381-1388, https://doi.org/10.1002/jbmr.340 (2011).

31. Drezner, M. K. Tumor-induced osteomalacia. Rev. Endocr. Metab. Disord. 2, 175-186 (2001).

32. Faul, C. et al. FGF23 induces left ventricular hypertrophy. J. Clin. Invest. 121, 4393-4408, https://doi.org/10.1172/JCI46122 (2011).

33. Brotto, M. \& Bonewald, L. Bone and muscle: Interactions beyond mechanical. Bone. 80, 109-114, https://doi.org/10.1016/j. bone.2015.02.010 (2015).

34. Ruppe, M. D. et al. Effect of fourmonthly doses of a human monoclonal anti-FGF23 antibody (KRN23) on quality of life in X-linked hypophosphatemia. Bone. Rep. 5, 158-162 (2016).

35. Suzanne et al, Thomas Carpenter. in ASBMR (Denver, Colorado, 2017).

36. Aono, Y. et al. Anti-FGF-23 neutralizing antibodies ameliorate muscle weakness and decreased spontaneous movement of Hyp mice. J. Bone Min. Res. 26, 803-810, https://doi.org/10.1002/jbmr.275 (2011).

37. Avin, K. G. et al. Fibroblast growth factor 23 does not directly influence skeletal muscle cell proliferation and differentiation or ex vivo muscle contractility. Am. J. Physiol. Endocrinol. Metab. 315, E594-E604, https://doi.org/10.1152/ajpendo.00343.2017 (2018).

38. Wacker, M. J. et al. Skeletal Muscle, but not Cardiovascular Function, Is Altered in a Mouse Model of Autosomal Recessive Hypophosphatemic Rickets. Front. Physiol. 7, 173, https://doi.org/10.3389/fphys.2016.00173 (2016).

39. Sinha, A., Hollingsworth, K. G., Ball, S. \& Cheetham, T. Improving the vitamin D status of vitamin D deficient adults is associated with improved mitochondrial oxidative function in skeletal muscle. J. Clin. Endocrinol. Metab. 98, E509-513, https://doi. org/10.1210/jc.2012-3592 (2013).

40. Schubert, L. \& DeLuca, H. F. Hypophosphatemia is responsible for skeletal muscle weakness of vitamin D deficiency. Arch. Biochem. Biophys. 500, 157-161, https://doi.org/10.1016/j.abb.2010.05.029 (2010).

41. Baczynski, R. et al. Effect of parathyroid hormone on energy metabolism of skeletal muscle. Kidney Int. 28, 722-727 (1985).

42. Smogorzewski, M., Piskorska, G., Borum, P. R. \& Massry, S. G. Chronic renal failure, parathyroid hormone and fatty acids oxidation in skeletal muscle. Kidney Int. 33, 555-560 (1988).

43. Miniou, P. et al. Gene targeting restricted to mouse striated muscle lineage. Nucleic Acids Res. 27, e27, htpps://doi.org/gnc027 [pii] (1999).

44. Leu, M. et al. Erbb2 regulates neuromuscular synapse formation and is essential for muscle spindle development. Dev. 130, 2291-2301, https://doi.org/10.1242/dev.00447 (2003).

45. Couasnay, G. et al. PiT1/Slc20a1 Is Required for Endoplasmic Reticulum Homeostasis, Chondrocyte Survival, and Skeletal Development. J. Bone Min. Res. 34, 387-398, https://doi.org/10.1002/jbmr.3609 (2019).

46. Collins, J. F., Bai, L. \& Ghishan, F. K. The SLC20 family of proteins: dual functions as sodium-phosphate cotransporters and viral receptors. Pflug. Arch. 447, 647-652 (2004).

47. Thomson, D. M. The Role of AMPK in the Regulation of Skeletal Muscle Size, Hypertrophy, and Regeneration. Int. J. Mol. Sci. 19, https://doi.org/10.3390/ijms19103125 (2018).

48. Drake, J. C., Wilson, R. J. \& Yan, Z. Molecular mechanisms for mitochondrial adaptation to exercise training in skeletal muscle. FASEB J. 30, 13-22, https://doi.org/10.1096/f.15-276337 (2016).

49. Handschin, C. et al. Abnormal glucose homeostasis in skeletal muscle-specific PGC-1alpha knockout mice reveals skeletal musclepancreatic beta cell crosstalk. J. Clin. Invest. 117, 3463-3474, https://doi.org/10.1172/JCI31785 (2007).

50. Olguin, H. C. \& Pisconti, A. Marking the tempo for myogenesis: Pax7 and the regulation of muscle stem cell fate decisions. J. Cell Mol. Med. 16, 1013-1025, https://doi.org/10.1111/j.1582-4934.2011.01348.x (2012).

51. Forand, A. et al. Disruption of the Phosphate Transporter Pit1 in Hepatocytes Improves Glucose Metabolism and Insulin Signaling by Modulating the USP7/IRS1 Interaction. Cell Rep. 16, 2736-2748, https://doi.org/10.1016/j.celrep.2016.08.012 (2016).

52. Theilen, N. T., Kunkel, G. H. \& Tyagi, S. C. The Role of Exercise and TFAM in Preventing Skeletal Muscle Atrophy. J. Cell Physiol. 232, 2348-2358, https://doi.org/10.1002/jcp.25737 (2017).

53. Mayr, J. A. et al. Deficiency of the mitochondrial phosphate carrier presenting as myopathy and cardiomyopathy in a family with three affected children. Neuromuscul. Disord. 21, 803-808, https://doi.org/10.1016/j.nmd.2011.06.005 (2011).

54. Bhoj, E. J. et al. Pathologic Variants of the Mitochondrial Phosphate Carrier SLC25A3: Two New Patients and Expansion of the Cardiomyopathy/Skeletal Myopathy Phenotype With and Without Lactic Acidosis. JIMD Rep. 19, 59-66, https://doi. org/10.1007/8904_2014_364(2015).

55. Kwong, J. Q. et al. Genetic deletion of the mitochondrial phosphate carrier desensitizes the mitochondrial permeability transition pore and causes cardiomyopathy. Cell Death Differ. 21, 1209-1217, https://doi.org/10.1038/cdd.2014.36 (2014).

56. Allen, D. L. et al. Cardiac and skeletal muscle adaptations. voluntary Wheel. running mouse. J. Appl. Physiol. 90, 1900-1908 (2001).

57. Egan, B. \& Zierath, J. R. Exercise metabolism and the molecular regulation of skeletal muscle adaptation. Cell Metab. 17, 162-184, https://doi.org/10.1016/j.cmet.2012.12.012 (2013).

58. Knochel, J. P. Models of hypophosphatemia and phosphate depletion. Adv. Exp. Med. Biol. 151, 191-198 (1982)

59. Bergwitz, C. \& Miyamoto, K. I. Hereditary hypophosphatemic rickets with hypercalciuria: pathophysiology, clinical presentation, diagnosis and therapy. Pflugers Arch., https://doi.org/10.1007/s00424-018-2184-2 (2018).

60. Iwata, M. et al. A novel tetracycline-responsive transgenic mouse strain for skeletal muscle-specific gene expression. Skelet. Muscle 8, 33, https://doi.org/10.1186/s13395-018-0181-y (2018).

61. Ma, Y. et al. FGF23 Is Not Required to Regulate Fetal Phosphorus Metabolism but Exerts Effects Within 12 Hours After Birth. Endocrinol. 158, 252-263, https://doi.org/10.1210/en.2016-1369 (2017).

62. Chande, S., Ho, B., Fetene, J. \& Bergwitz, C. Transgenic mouse model for conditional expression of influenza hemagglutinin-tagged human SLC20A1/PIT1. PLoS One 14, e0223052, https://doi.org/10.1371/journal.pone.0223052 (2019).

63. Giovannini, D., Touhami, J., Charnet, P., Sitbon, M. \& Battini, J. L. Inorganic phosphate export by the retrovirus receptor XPR1 in metazoans. Cell Rep. 3, 1866-1873, https://doi.org/10.1016/j.celrep.2013.05.035 (2013).

64. Legati, A. et al. Mutations in XPR1 cause primary familial brain calcification associated with altered phosphate export. Nat. Genet. 47, 579, https://doi.org/10.1038/ng.3289 (2015).

65. Wild, R. et al. Control of eukaryotic phosphate homeostasis by inositol polyphosphate sensor domains. Sci. 352, 986-990, https:// doi.org/10.1126/science.aad9858 (2016).

66. Ansermet, C. et al. Renal Fanconi Syndrome and Hypophosphatemic Rickets in the Absence of Xenotropic and Polytropic Retroviral Receptor in the Nephron. J. Am. Soc. Nephrol. 28, 1073-1078, https://doi.org/10.1681/ASN.2016070726 (2017). 
67. Ovejero, D., Gafni, R. I. \& Collins, M. T. 1,25-Dihydroxyvitamin D as Monotherapy for XLH: Back to the Future? J. Bone Min. Res. 31, 925-928, https://doi.org/10.1002/jbmr.2858 (2016).

68. Festing, M. H., Speer, M. Y., Yang, H. Y. \& Giachelli, C. M. Generation of mouse conditional and null alleles of the type III sodiumdependent phosphate cotransporter PiT-1. Genes. 47, 858-863, https://doi.org/10.1002/dvg.20577 (2009).

69. Wagner, C. A., Rubio-Aliaga, I. \& Hernando, N. Renal phosphate handling and inherited disorders of phosphate reabsorption: an update. Pediatr. Nephrol., https://doi.org/10.1007/s00467-017-3873-3 (2017).

70. Truett, G. E. et al. Preparation of PCR-quality mouse genomic DNA with hot sodium hydroxide and tris (HotSHOT). Biotechniques 29, 52-54, https://doi.org/10.2144/00291bm09 (2000).

71. Li, Y. et al. Response of Npt2a knockout mice to dietary calcium and phosphorus. PLOS ONE 12, e0176232, https://doi.org/10.1371/ journal.pone.0176232 (2017).

72. Saria, A. \& Lundberg, J. M. Evans blue fluorescence: quantitative and morphological evaluation of vascular permeability in animal tissues. J. Neurosci. Methods 8, 41-49, https://doi.org/10.1016/0165-0270(83)90050-x (1983).

73. Sahay, A. et al. Increasing adult hippocampal neurogenesis is sufficient to improve pattern separation. Nat. 472, 466-470, https://doi. org/10.1038/nature09817 (2011).

74. Duman, C. H., Schlesinger, L., Russell, D. S. \& Duman, R. S. Voluntary exercise produces antidepressant and anxiolytic behavioral effects in mice. Brain Res. 1199, 148-158, https://doi.org/10.1016/j.brainres.2007.12.047 (2008).

75. Wang, X. \& Seed, B. A PCR primer bank for quantitative gene expression analysis. Nucl. Acid. Res. 31, 1-8 (2003).

76. Divakaruni, A. S., Rogers, G. W. \& Murphy, A. N. Measuring Mitochondrial Function in Permeabilized Cells Using the Seahorse XF Analyzer or a Clark-Type Oxygen Electrode. Current protocols in toxicology 60, 25.22.21-16, https://doi.org/10.1002/0471140856. tx2502s60 (2014)

77. Salabei, J. K., Gibb, A. A. \& Hill, B. G. Comprehensive measurement of respiratory activity in permeabilized cells using extracellular flux analysis. Nat. Protoc. 9, 421-438, https://doi.org/10.1038/nprot.2014.018 (2014).

\section{Acknowledgements}

We are grateful to the Cell Biology Core of the Yale Diabetes Research Center (NIH/NIDDK P30 DK045735) for help with fluorescent microscopic analysis and access to their ABI qPCR instrument, to the Yale O'Brien Center NIH (NIH/NIDDK P30DK079310) for training and access to VWR devices, and biochemical testing of mouse serum and urine samples, to the Mouse Research Pathology Core for histologic slide preparation, to the Yale Mouse Metabolic Phenotyping Core (NIH/NIDDK U24 DK-059635 and NIH/NIDDK R01 DK116774 (G.I.S)) for access to their grip strength device and Seahorse analyzer, and to the Yale Center for Cellular and Molecular Imaging (YCCMI) for help with electron microscopic analysis. N.H. and CAW were supported by the Swiss National Science Foundation (grant no 31003A_176125). D.P. was supported by the Austrian Science Fund (FWF), project no. J 3267.

\section{Author contributions}

S.C., B.B.H., J.F. J.S. and D.C. performed all experiments. D.P., A.N. and G.I.S. provided training and devices for grip strength studies. C.Z. performed necropsies and pathological analysis of $s m P i t 1^{-1-}$; smPit2 ${ }^{-l-}$ mice. M.J. and G.I.S. provided the HSA-Cre mice, N.W.C. and C.M.G. provided the Pit $1^{f l f l}$ mice, N.H. and C.A.W. provided the Pit $2^{f l / f l}$ mice, C.B. conceived the work and together with S.C. and D.C. processed all results, performed statistical analysis and wrote the manuscript.

\section{Competing interests}

Sampada Chande, Daniel Caballero, Bryan B. Ho, Jonathan Fetene, Juan Serna, Dominik Pesta, Ali Nasiri, Michael Jurczak, Nicholas W. Chavkin, Nati Hernando, Cecilia M. Giachelli and Caroline Zeiss declare that they have no conflict of interest. Carsten A. Wagner has served on advisory boards to Bayer and Medice and received honoraria from Medice. Gerald I. Shulman serves on the advisory boards for Merck, Novo Nordisk, AstraZeneca, Gilead Sciences and Janseen Research and Development and he receives investigator-initiated support from AstraZeneca, Gilead Sciences and Merck. Clemens Bergwitz has received research support from Nutricia North America, Bethesda, MD, USA, for an unrelated project. He serves on the advisory board for Bayer.

\section{Additional information}

Supplementary information is available for this paper at https://doi.org/10.1038/s41598-020-59430-4.

Correspondence and requests for materials should be addressed to C.B.

Reprints and permissions information is available at www.nature.com/reprints.

Publisher's note Springer Nature remains neutral with regard to jurisdictional claims in published maps and institutional affiliations.

(c) (i) Open Access This article is licensed under a Creative Commons Attribution 4.0 International cc. License, which permits use, sharing, adaptation, distribution and reproduction in any medium or format, as long as you give appropriate credit to the original author(s) and the source, provide a link to the Creative Commons license, and indicate if changes were made. The images or other third party material in this article are included in the article's Creative Commons license, unless indicated otherwise in a credit line to the material. If material is not included in the article's Creative Commons license and your intended use is not permitted by statutory regulation or exceeds the permitted use, you will need to obtain permission directly from the copyright holder. To view a copy of this license, visit http://creativecommons.org/licenses/by/4.0/.

(C) The Author(s) 2020 